\title{
Assessing the value of commonly used methods for measuring customer value: a multi-setting empirical study
}

\author{
Sara Leroi-Werelds • Sandra Streukens • \\ Michael K. Brady • Gilbert Swinnen
}

Received: 28 January 2013 / Accepted: 21 October 2013 / Published online: 1 December 2013

(C) Academy of Marketing Science 2013

\begin{abstract}
Despite the importance of customer value, considerable divergence of opinion exists on how to adequately conceptualize and measure this construct. In this study, four commonly used methods for measuring customer value (i.e., the methods proposed by Dodds et al. (1991), Gale (1994), Holbrook (1999) and Woodruff and Gardial (1996)) are compared. First and foremost, the psychometric properties of the different methods are evaluated. Next, the authors compare the predictive ability of the different methods with respect to key outcome variables (i.e., satisfaction, word of mouth, repurchase intention). Finally, the methods are compared based on their relative practicality and actionability. The authors' findings show that each method has its own benefits and costs and should be used based on its suitability for a particular application. The paper culminates with a prescriptive flowchart that summarizes the main findings and provides direction for choosing the optimal value measurement method.
\end{abstract}

Keywords Customer value $\cdot$ Perceived value $\cdot$ Measurement methods $\cdot$ Comparison

S. Leroi-Werelds $(\triangle) \cdot$ S. Streukens $\cdot$ G. Swinnen

Department of Marketing \& Strategy, Hasselt University,

Agoralaan - D, 3590 Diepenbeek, Belgium

e-mail: sara.leroiwerelds@uhasselt.be

S. Streukens

e-mail: sandra.streukens@uhasselt.be

G. Swinnen

e-mail: gilbert.swinnen@uhasselt.be

M. K. Brady

Department of Marketing, College of Business, Florida State

University, 821 Academic Way, P.O. Box 3061110,

Tallahassee, FL, USA

e-mail: mbrady@fsu.edu
In today's increasingly competitive business world, in which customers are more demanding and more value conscious than ever before (Sweeney and Soutar 2001), it is indispensable for organizations to understand how to assess value from the customer's perspective (Sweeney and Soutar 2001; Woodruff 1997). Customer value, which can be defined as a tradeoff between the offering's benefits and costs perceived by the customer, has been widely recognized as an essential ingredient for firm performance (Slater 1997; Woodruff 1997). Additionally, the importance of customer value is underscored by Vargo and Lusch (2004) when they presented service-dominant logic. In their groundbreaking Journal of Marketing article (Vargo and Lusch 2004), they refer to value more than 50 times and it plays a central role in at least three of their foundational premises (see also Woodruff and Flint 2006).

Because of the importance of customer value to the marketing literature as well as marketing practice, it has been extensively studied in recent years. However, there is a pressing need for further understanding of how value should be measured (e.g., Sánchez-Fernández et al. 2009; Sweeney and Soutar 2001) since "making customer value strategies work begins with an actionable understanding of the concept itself" (Woodruff 1997, p. 141). Although a great number of value measurement methods are offered in the literature, no empirical work exists that considers the relative performance of the most popular methods. We argue that this is a critical oversight, as empirical evidence concerning how to optimally conceptualize and measure perceived customer value represents a necessary condition for realizing the full potential of customer value management.

In response to this gap in the literature, we aim to assess and compare the performance of four commonly used customer value measurement methods (i.e., Dodds et al. 1991; Gale 1994; Holbrook 1999; Woodruff and Gardial 1996). We compare these methods with regard to two quantitative and 
two subjective topics. First, we investigate the measurement model associated with the four methods by examining their psychometric properties, which is a crucial step in the evaluation of measurement methods. Second, we examine the structural models associated with the four methods by comparing their abilities to predict key customer outcome measures (i.e., customer satisfaction, repurchase intentions, and word of mouth). Third, we evaluate the practicality of the different methods both from the researcher's and practitioner's points of view. Finally, we evaluate the actionability of the four methods in terms of their abilities to offer specific directions for improvement. To ensure cross-validation of results, model comparisons take place across four different product settings. The paper culminates with a prescriptive flowchart that offers advice on the most suitable measurement approach across a variety of commonly encountered settings.

We organize the rest of this paper as follows. First, we give a brief literature review in which we describe customer value, present the four methods for measuring customer value that take central stage in this study, and discuss their similarities and differences. Second, we describe the four topics of comparison. Next, we discuss the research design, and subsequently, we describe our findings with respect to each of the topics. Finally, we discuss the results and limitations, and make suggestions for further research.

\section{Literature review}

\section{Conceptual background on customer value}

A review of the existing literature on customer value provides some key insights into the nature of the concept. First, although a number of definitions have been put forth, the one proposed by Zeithaml (1988, p. 14), "the consumer's overall assessment of the utility of a product based on perceptions of what is received and what is given," is perhaps the most universally accepted definition of customer value (e.g., Chen and Dubinsky 2003; Flint et al. 2002; Ruiz et al. 2008). Second, customer value is perceived by the customer; therefore, it is the customer who defines the value of a product or service and not the supplier (Vargo and Lusch 2004; Woodruff 1997). Third, customer value is personal. Each customer perceives value based upon personal characteristics such as his/her own needs and desires, knowledge, previous experience, and financial resources (Grönroos 2011; Holbrook 1999; Woodall 2003). Fourth, the value perceived by the customer depends on circumstances, time frame, and location (Holbrook 1999; Woodruff 1997; Woodruff and Gardial 1996). For example, a hot cup of tea can be very valuable in winter, but an ice cold cup of lemonade may be preferred in summer. Fifth, customer value implies an interaction between a subject (the customer) and an object (e.g., a product, a service, a store). This latter characteristic distinguishes customer value from customer values, which are the customer's core values, purposes, and goals in life (Holbrook 1999; Woodruff 1997; Woodruff and Gardial 1996). Sixth, customer value is experiential, which means that it resides not in the product purchased or the brand chosen, but in the consumption experiences derived therefrom. Hence, the subject (i.e., the customer) interacts with the object (i.e., the product or service) by using or experiencing it in some way (Holbrook 1999). This perspective is in line with the notion of value-inuse, which implies that real value only emerges during use, since "value is not created and delivered by the supplier but emerges during usage in the customer's process of value creation" (Grönroos and Ravald 2011, p. 8). The firm facilitates the customer's value creation process by producing and delivering resources that represent potential value (or expected value-in-use).

In this study, we focus on product settings in business-toconsumer (hereafter B-to-C) physical goods markets. Although value is a key construct in nearly every consumption setting, recent research in B-to-B (e.g., Blocker et al. 2011; Ulaga and Eggert 2006) and service (e.g., Chan et al. 2010) markets suggests that measuring value in those settings requires the consideration of personal interactions. This perspective is in line with the notion of value co-creation mentioned by Grönroos and colleagues (Grönroos 2011; Grönroos and Ravald 2011; Grönroos and Voima 2013). They mention that during direct interactions with the customer, the supplier gets opportunities for value co-creation, which implies that the supplier can influence the customer's process of value creation, with the intention of enhancing the level of value. Because of the fundamental nature of interactions in service settings and business markets, personal interactions between the customer and the supplier can be a source of value above and beyond the value of the core offering itself (Ulaga and Eggert 2006). Hence, personal interactions should be taken into account when measuring customer value in those markets. Because the four value measures assessed here do not capture personal interactions, we place our focus on the perceived value of physical goods in B-to-C settings.

\section{Customer value conceptualizations}

An overview of the literature reveals two main approaches to the operationalization of customer value: a one-dimensional approach and a multi-dimensional approach. The onedimensional approach to customer value represents the origin of the study of customer value (Sánchez-Fernández and Iniesta-Bonillo 2007). According to the one-dimensional view, customer value is "a single overall concept that can be measured by a self-reported item (or set of items) that evaluates the consumer's perception of value" (Sánchez-Fernández and Iniesta-Bonillo 2007, p. 430). 
One of the first approaches to measure customer value is the one-dimensional measurement method developed by Dodds et al. (1991). These authors defined customer value as "a cognitive tradeoff between perceived quality and sacrifice" (Dodds et al. 1991, p. 316). On the basis of this definition, they measure customer value by asking respondents five summary questions concerning the overall value of the product or service (see Appendix B for a list of the items). As can be seen in the wording of the items, this approach focuses on the monetary exchange and the overall price-quality relationship. Empirical studies using the measurement scale of Dodds et al. (1991) include Teas and Agarwal (2000), Agarwal and Teas (2001), Baker et al. (2002), Chen and Dubinsky (2003) and Caruana and Fenech (2005).

Although an often-mentioned advantage of the onedimensional measurement method is its simplicity and ease of implementation (Lin et al. 2005), many researchers (e.g., Ruiz et al. 2008; Sweeney and Soutar 2001) point out that customer value is too complex to be captured by a onedimensional measurement method. As a response to this critique, so-called multi-dimensional approaches have been put forth, which consider customer value as consisting of several interrelated components or dimensions (Sánchez-Fernández and Iniesta-Bonillo 2007).

We pause here to elaborate on means-end theory as a foundation for understanding the multi-dimensional approaches for studying customer value. Means-end theory (Gutman 1982) provides the necessary theoretical background of how customers view products. It states that the way products are related to customers can be represented by three levels: attributes, consequences, and desired end-states. Attributes are physical characteristics or features of a product such as size, shape, or on-time delivery. Consequences are more subjective experiences resulting from product use, such as a reduction in lead time or a pleasant experience (Gutman 1982; Woodruff and Gardial 1996). Finally, desired end-states are the customer's core values, purposes, and goals in life and can be formally defined as "centrally held and enduring beliefs about right and wrong, good and bad that cut across situations and products or services" (Woodruff 1997, p. 141). The key premise of means-end theory is that individuals are goal-directed and use products as a way to achieve valued states of being such as happiness, security, accomplishment (Gutman 1982). Products and services - and their related customer value - are thus means to reach those end-states. With regard to the operationalization of customer value, some researchers adopted an attribute-based view, whereas others prefer a consequence-based view on the topic. The key difference here is whether the items refer to qualities the product possesses (attributes) versus qualities the product delivers (consequences).

Gale (1994, p. xiv) focuses on product attributes and defines customer value as "market perceived quality adjusted for the relative price of your product." The basic premise underlying Gale's (1994) 'Customer Value Analysis' is that customer value equals the difference between a weighted quality score (termed market-perceived quality) and a weighted price score (termed market-perceived price). The process of creating a market-perceived quality score is as follows:

1. Make a list of the product attributes that customers and competitor's customers find important. These attributes are known by the company or elicited from in-depth or focus group interviews, and they cover all relevant aspects related to perceived quality.

2. Establish how the various quality attributes are weighted in the customer's decision. This can be done by asking customers to evaluate the importance of the various attributes.

3. Ask customers to rate the performance of the product and competing products on each of the attributes.

4. Multiply the performance score on each attribute by the weight of that attribute, and add the results to get the market-perceived quality score.

The same procedure holds for creating a market-perceived price score. Based on the market-perceived quality score and market-perceived price score, the firm can evaluate the value of its products and compare it with the value of competing products. Authors following Gale's (1994) Customer Value Analysis include Laitamäki and Kordupleski (1997), Lam et al. (2004) and Setijono and Dahlgaard (2007).

Woodruff and Gardial (1996) argue that value creation takes place at the consequence level and that consequences can be positive or negative. More formally, value is considered to be "the result of the trade-off between the positive and negative consequences of product use as perceived by the customer" (p. 57). According to Woodruff and Gardial (1996), many firms view their output as a bundle of attributes and focus their research and development on improving their offering by adding, refining, or deleting attributes, whereas customers are interested in the consequences of using or possessing the product. They argue that a shift in focus from attributes to consequences will result in value creation that leads to a more pronounced and sustainable competitive advantage. Rather than simply focusing on attributes, firms must understand how and why customers prefer certain product attributes, which requires understanding the consequences of product use (Overby et al. 2004).

Finally, there are different classifications of types of customer value. With regard to such typologies, Holbrook's method is considered "the most comprehensive approach to the value construct because it captures more potential sources of value than do other conceptualizations" (SánchezFernández et al. 2009, p. 97). Further, Holbrook's typology encompasses other measurement methods proposed in the literature. For example, the Perceived Value (PERVAL) scale 
suggested by Sweeney and Soutar (2001) and the Experience Value Scale (EVS) proposed by Mathwick et al. (2001) are value typologies that are based on or fit within Holbrook's (1999) value typology. Holbrook (1999, p. 5) defined customer value as "an interactive relativistic preference experience" and developed a customer value framework that reflects three underlying dimensions: (1) extrinsic value versus intrinsic value (i.e., an offering appreciated for its functional, utilitarian ability to achieve something versus an offering appreciated as an end-in-itself), (2) self-oriented value versus other-oriented value (i.e., an offering prized for the effect it has on oneself versus the effect it has on others), and (3) active value versus reactive value (i.e., the customer acts on the object versus the object acts on the customer). Using the three dimensions outlined above, Holbrook (1999) developed a matrix representing eight types of customer value: efficiency, excellence, status, esteem, play, aesthetics, ethics, and spirituality.

The Holbrook typology involves the co-existence of different types of customer value, meaning that a consumption experience can entail many — or even all — of the value types identified in the typology (Holbrook 1999). However, some of the value types in Holbrook's framework are related in such a way that it is extremely difficult to operationalize them separately. For that reason, some authors suggest combining these value types in an overarching category. In particular, the demarcation between status and esteem can be problematic (Holbrook 1999) because "the active nature of status and the reactive nature of esteem tend to blur together in ways that render the two hard to distinguish" (Holbrook 1999, p.188). Therefore, we follow previous research by combining status and esteem in an overarching category called social value (Bourdeau et al. 2002; Gallarza and Gil-Saura 2006; Sánchez-Fernández et al. 2009; Sweeney and Soutar 2001). Social value arises when one's own consumption behavior serves as a means to influence the responses of others (Holbrook 2006). Similarly, ethics and spirituality can be combined under the heading of altruistic value, as "both lie outside the sphere of ordinary marketplace exchanges" (Sánchez-Fernández et al. 2009, p. 101). One can define altruistic value as "a concern for how my own consumption behavior affects others where this experience is viewed as a self-justifying end-in-itself" (Holbrook 2006, p. 716).

To summarize, the conceptualizations of Dodds et al. (1991), Gale (1994), Woodruff and Gardial (1996) and Holbrook (1999) take center stage in our study. All four methods encompass the tradeoff approach mentioned in Zeithaml's (1988) definition and have been commonly used in both applied and academic research. The method of Dodds et al. (1991) is a one-dimensional approach, whereas the others are multi-dimensional. With regard to the multidimensional approaches, the method of Gale (1994) focuses on the attributes, whereas the methods of Woodruff and
Gardial (1996) and Holbrook (1999) include the consequences of product use.

Key customer outcomes of value

In this paper, we studied customer value in its relationship with three outcome variables: satisfaction, word of mouth, and repurchase intentions. These particular variables were selected for three reasons: First, we opted for outcome variables for which there exists considerable empirical evidence that they are related to actual behavior and (financial) performance. A growing body of research links these three outcome variables with market share (Anderson et al. 1994; Morgan and Rego 2006), long-term profitability (Anderson et al. 1997; Bernhardt et al. 2000; Villanueva et al. 2008; Mittal et al. 2005), accounting returns (Ittner and Larcker 1998), new customer acquisition (Trusov et al. 2009), shareholder value (Anderson et al. 2004; Gruca and Rego 2005; Morgan and Rego 2006), stock prices (Fornell et al. 2006), and consumer spending (Fornell et al. 2010). Second, the chain of effects between perceived customer value and the outcome variables under study are rooted in Bagozzi's (1992) appraisal $\rightarrow$ emotional response $\rightarrow$ coping framework (Gotlieb et al. 1994; Cronin et al. 2000) and, taken together, they capture the key processes leading to positive outcomes for firms. Based on this framework, the initial product or service evaluation (i.e., appraisal) leads to satisfaction (i.e., emotional response) that, in turn, drives behavioral intentions (i.e., coping) (Gotlieb et al. 1994). ${ }^{1}$ Third, we opted for outcome variables and linkages that are well-established and validated in the marketing literature. Prior research has indicated that customer value is an important antecedent to satisfaction, repurchase intentions, and word of mouth (Bolton and Drew 1991; Cronin et al. 2000; Lai et al. 2009). Hence, we developed the structural model presented in Fig. 1 to evaluate the performance of the four measurement methods.

\section{Comparison of methods}

The primary objective of our study is to compare the four value measurement methods with regard to two quantitative and two subjective criteria. The quantitative criteria include the assessments of the measurement and structural models related to the four methods. More specifically, we look at the psychometric properties and predictive ability associated with each of the four methods. The subjective criteria include each method's practicality and actionability, which generally refer

\footnotetext{
${ }^{1}$ In line with the work of Anderson et al. (1994) and Cronin et al. (2000), we define customer satisfaction as the cumulative evaluation that is based on all experiences with the supplier's offering over time and we included a direct link between value and behavioral intentions.
} 


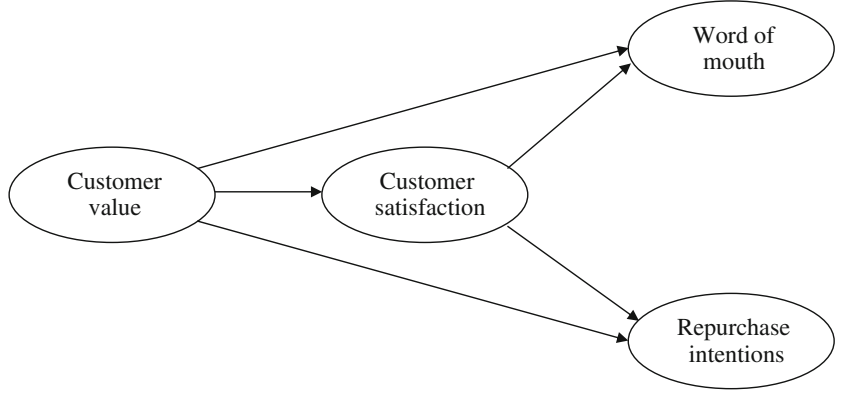

Fig. 1 Structural model

to ease of use and ability to offer specific directions for improvement. We describe each of the four criteria in more detail below.

Measurement model: psychometric properties

We start our comparison with evaluating the measurement models in terms of how well the value construct is measured by the indicator variables, both individually and jointly (Hair et al. 2011). Therefore, we examine the psychometric properties of all first-order constructs used in our study. We note, however, that it is crucial to distinguish between reflective and formative scales (Hair et al. 2011; MacKenzie et al. 2005).

Regarding the reflective scales, relevant psychometric properties include unidimensionality, internal consistency reliability, item validity, within-method convergent validity, and discriminant validity. Unidimensionality refers to the existence of a single construct underlying a set of items and is assessed following the procedure suggested by Sahmer et al. (2006). According to this two stage procedure, a set of items is unidimensional if: (1) the first eigenvalue of the correlation matrix of items exceeds one, and (2) the second eigenvalue is smaller than one. Thus, this implies testing the following hypotheses:

(1) $\mathrm{H}_{0}: \lambda_{1}=1 \quad \mathrm{H}_{\mathrm{a}}: \lambda_{1}>1$

(2) $\mathrm{H}_{0}: \lambda_{2}=1 \quad \mathrm{H}_{\mathrm{a}}: \lambda_{2}<1$

According to Karlis et al. (2003), the first hypothesis $\left(\mathrm{H}_{\mathrm{a}}\right.$ : $\left.\lambda_{1}>1\right)$ can be accepted if

$\lambda_{1}>1+2 \sqrt{\frac{p-1}{n-1}}$

where $p$ equals the number of indicators and $n$ indicates the sample size. The second hypothesis implies testing whether the second eigenvalue is smaller than one $\left(\mathrm{H}_{\mathrm{a}}: \lambda_{2}<1\right)$.

Internal consistency reliability refers to the degree to which the items intended to measure the same latent construct have similar scores. Cronbach's alpha has traditionally been used to assess the internal consistency reliability of reflective constructs. In general, the accepted threshold for Cronbach's alpha is .70 or above (MacKenzie et al. 2011).
For reflective constructs, the validity of the individual items (i.e., item validity) can be assessed by determining whether the relationship between each item and its latent construct is large and significant. A value greater than .70 would suggest an adequate level of item validity because it suggests the item is accounting for more measurement variance than error (MacKenzie et al. 2011; Hair et al. 2011). Within method convergent validity refers to the extent to which the different indicators of the same construct are in agreement. A common measure to examine convergent validity is the average variance extracted estimate (AVE), as defined by Fornell and Larcker (1981). Based on this test, a construct possesses convergent validity if the majority of the variance in the reflective indicators is accounted for by the underlying latent construct rather than by measurement error (i.e., AVE $>.50$ ).

A necessary condition for discriminant validity is that the shared variance between the latent variable and its indicators is larger than the variance shared with other variables. To test for this, the AVE is compared with the squared correlations among constructs (Fornell and Larcker 1981). This test is based on the principle that each construct should be more highly related to its own indicators than to other constructs (Chin 2010).

Formative constructs demand a different approach to evaluate the measurement model (Diamantopoulos and Winklhofer 2001) and should only be evaluated by means of their item and discriminant validity. Item validity is captured by the significance of the path from the indicator to the latent construct (MacKenzie et al. 2011). Indicators that do not have a significant loading on the construct can be considered for elimination. However, "it is important to remember that subdimensions should not be eliminated unless all of the essential aspects of the focal construct domain are captured by the remaining sub-dimensions" (MacKenzie et al. 2011, p. 316). Discriminant validity of the formative constructs can be evaluated by testing whether the constructs are less than perfectly correlated. This implies assessing whether an absolute value of 1 falls within two standard errors of the latent variable correlations (MacKenzie et al. 2005).

Structural model: predictive ability

Our second comparison criterion relates to the structural model. More specifically, we look at the ability of each method to predict key outcome variables (i.e., satisfaction, word of mouth, repurchase intentions) drawn from the literature (e.g., Cronin et al. 2000). From a theoretical perspective, expanding our knowledge of the predictive properties of these commonly used value measurement methods is needed to understand the effects of customer value in relation to other constructs. Additionally, information about the behavior of the various customer value measurement methods in the context of other relevant constructs allows for greater understanding of the 
broader nomological network. Based on the existing literature, we put forward two hypotheses with regard to the predictive ability of the various methods.

First, we expect that multi-dimensional methods perform better than one-dimensional methods. This expectation is fueled by the fact that one-dimensional methods "cannot discern the complex nature of perceived value" (Lin et al. 2005, p. 319). Thus, we hypothesize the following.

H1: With regard to predictive ability, multi-dimensional value conceptualizations perform better than onedimensional value conceptualizations.

Second, we expect methods that include benefits and sacrifices at the consequence level to perform better than methods that do not. This expectation is in line with the servicedominant logic proposed by Vargo and Lusch (2004) and more specifically with the concept of 'value-in-use'. Lusch and Vargo (2006, p. 44) state that "there is no value until an offering is used-experience and perception are essential to value determination." This implies that value is fundamentally derived and determined in use (i.e., consequences) rather than in exchange (i.e., attributes) (Vargo et al. 2008), which is consistent with our expectation that value should be measured at the consequence level rather than at the attribute level. Therefore, we put forward the following hypothesis.

H2: With regard to predictive ability, value conceptualizations that assess benefits and sacrifices at the consequence level perform better than value conceptualizations that do not assess benefits and sacrifices at the consequence level.

\section{Practicality}

In this study, we approach practicality from two perspectives: ease of use and questionnaire length. Ease of use implies that the method is straightforward and simple and, as a result, can easily be used, even by non-experts (Devlin et al. 2003; Stewart 1992). For example, if interviews are necessary to generate items before a particular method can be used, this process is very time consuming and is therefore a drawback. With regard to questionnaire length, a value measurement method with many items may fatigue respondents and therefore researchers should account for survey length when choosing a value measurement method (Drolet and Morrison 2001). Indeed, as shown by Deutskens et al. (2004), questionnaire length has a negative effect on response rates, completion rates, and response quality.

\section{Actionability}

The primary purpose of any measurement approach is to gain information (Drolet and Morrison 2001), and thus we argue that information is another important basis on which each of the measurement methods should be evaluated. However, we go one step further by assessing 'actionability', which implies that the information gathered by the measurement method can be easily translated into actionable guidelines. With regard to value measurement methods, the primary goal is to gather useful information to identify directions for improvement (Woodruff 1997). Leading companies are looking for measurement tools that provide insight into the strengths and weaknesses of the company and an increased understanding of what is important to the customer (Devlin et al. 2003; Rust et al. 2004). Thus, the choice of a measurement method not only affects the reliability and validity of the results, but also how the results can be used (Devlin et al. 2003).

\section{Methodology}

\section{Sampling}

We collected data in cooperation with a European online research bureau. Although respondents were self-selected, they were disqualified if they did not use or buy the product they evaluated or did not pay for the product themselves. To ensure cross-validation of results, data were gathered across several settings. The choice of settings was guided by the Foote, Cone, and Belding (FCB) grid (Vaughn 1980), which classifies customers' purchase decisions on two dimensions: involvement (high/low) and type of offering (think/feel). The products selected as research contexts for our study are soft drinks (low involvement, feel), toothpaste (low involvement, think), day cream (high involvement, feel) and DVD players (high involvement, think). A manipulation check was conducted based on the scale suggested by Ratchford (1987). Regarding the level of involvement, as expected, day cream and DVD players were evaluated as higher involvement ( $M=4.94,4.72$ respectively) than toothpaste and soft drinks $(M=4.14,4.26, p<.001)$. With respect to the type of offering (think vs. feel), soft drinks $(M=4.91)$ and day cream $(M=4.76)$ were judged to be higher feel than toothpaste $(M=4.39)$ and DVD players $(M=3.99$, $p<.001)$.

Each respondent was asked to answer the items associated with only one of the four value measurement methods under study, and for only one of the four settings. Data were collected from a total of 3,360 respondents. More specifically, we collected data from 16 different samples (i.e., 4 methods in 4 different settings), each having a sample size of 210 respondents. The rationale behind this choice is threefold. First, we tried to keep the amount of time and effort (and hence fatigue) from the respondents as low as possible. Second, we tried to avoid carry-over effects among the different value measurement approaches. Finally, restricting ourselves to betweensubject variance allows us to draw statistically valid 
conclusions among all possible combinations of value measurement methods. Table 1 displays key demographic characteristics.

\section{Questionnaire design}

All questionnaires were administered in Dutch and identical in terms of the measurement instruments for customer satisfaction, repurchase intentions, and word of mouth. What differed across the questionnaires was the value measurement method, which was adapted to the particular setting. All individual items are listed in Appendices A and $\mathrm{B}$ and are evaluated on 9-point Likert scales unless indicated otherwise.

Dodds et al.'s (1991) approach To assess the performance of the measurement approach suggested by Dodds et al. (1991), we used the five items suggested by the original authors.

Gale's (1994) approach To generate items for Gale's (1994) Customer Value Analysis, we carried out in-depth interviews using the laddering technique (Woodruff and Gardial 1996) and listed the attributes that people found most important in the four different settings (see Appendix A). In total, 28 interviews were conducted with respondents that had experience with the product under investigation (DVD player $n=7$; day cream $n=6$; soft drinks $n=7$; toothpaste $n=8$ ). The number of respondents in each setting was determined using the procedure suggested by Strauss and Corbin (1998). Since Gale's (1994) method implies a relative approach for measuring customer value, we asked respondents to evaluate the product attributes relative to the competition with labels ranging from $X Y Z$ is much better to $X Y Z$ is much worse (Babakus et al. 2004). In line with Gale's (1994) measurement method, a directly assessed importance weight was needed for each attribute. However, because the number of attributes was considerably large, point allocation - as proposed by Gale (1994) - was not an option. Thus, we asked the respondents to rate the importance of each attribute on a Likert scale anchored at 1 (very unimportant) and 9 (very important).

Woodruff and Gardial's (1996) approach The generation of items for the measurement method proposed by Woodruff and Gardial (1996) was based entirely on the results of the laddering interviews mentioned above (see Appendix A).

Holbrook's (1999) approach For the measurement of Holbrook's (1999) typology, we used existing scales wherever possible (e.g., excellence: Oliver 1997, efficiency: Ruiz et al. 2008, social value: Sweeney and Soutar 2001, play: Petrick 2002) and adapted them to the particular product settings by means of the laddering interviews described above. An existing scale for aesthetic value was not available, so we used the results of the laddering interviews to generate items. Altruistic value was not mentioned in the interviews, so we did not take this value type into account in our empirical study (Gallarza and Gil-Saura 2006).

Outcome variables To assess customer satisfaction, Wirtz and Lee's (2003) 11-point scale was used. Repurchase intentions
Table 1 Demographic characteristics

\begin{tabular}{|c|c|c|c|c|c|c|}
\hline \multirow[t]{2}{*}{ Setting } & \multirow[t]{2}{*}{ Method } & \multirow[t]{2}{*}{ Sample size } & \multicolumn{2}{|l|}{ Gender } & \multicolumn{2}{|l|}{ Age } \\
\hline & & & Male & Female & M & SD \\
\hline \multirow[t]{4}{*}{ Toothpaste } & Dodds et al. & 210 & $47.10 \%$ & $52.90 \%$ & 48.64 & 14.49 \\
\hline & Gale & 210 & $37.10 \%$ & $62.90 \%$ & 43.83 & 14.60 \\
\hline & Woodruff and Gardial & 210 & $55.20 \%$ & $44.80 \%$ & 47.28 & 14.14 \\
\hline & Holbrook & 210 & $51.00 \%$ & $49.00 \%$ & 48.51 & 14.41 \\
\hline \multirow[t]{4}{*}{ Soft drink } & Dodds et al. & 210 & $46.70 \%$ & $53.30 \%$ & 48.69 & 13.35 \\
\hline & Gale & 210 & $44.80 \%$ & $55.20 \%$ & 50.09 & 11.87 \\
\hline & Woodruff and Gardial & 210 & $50.00 \%$ & $50.00 \%$ & 47.25 & 13.13 \\
\hline & Holbrook & 210 & $42.40 \%$ & $57.60 \%$ & 48.29 & 13.69 \\
\hline \multirow[t]{4}{*}{ DVD player } & Dodds et al. & 210 & $80.50 \%$ & $19.50 \%$ & 49.82 & 14.75 \\
\hline & Gale & 210 & $60.00 \%$ & $40.00 \%$ & 46.68 & 11.92 \\
\hline & Woodruff and Gardial & 210 & $57.10 \%$ & $42.90 \%$ & 47.99 & 11.70 \\
\hline & Holbrook & 210 & $59.00 \%$ & $41.00 \%$ & 48.19 & 12.97 \\
\hline \multirow[t]{4}{*}{ Day cream } & Dodds et al. & 210 & $21.00 \%$ & $79.00 \%$ & 46.11 & 12.04 \\
\hline & Gale & 210 & $21.40 \%$ & $78.60 \%$ & 47.00 & 13.69 \\
\hline & Woodruff and Gardial & 210 & $21.90 \%$ & $78.10 \%$ & 46.43 & 13.05 \\
\hline & Holbrook & 210 & $14.30 \%$ & $85.70 \%$ & 46.87 & 13.80 \\
\hline TOTAL & & 3,360 & $44.34 \%$ & $55.66 \%$ & 47.60 & \\
\hline
\end{tabular}


and word of mouth were measured using the scales developed by Zeithaml et al. (1996).

\section{Parameter estimation}

Partial Least Squares (PLS) path modeling was used to analyze the data. PLS is the preferred approach in our study for at least two reasons. First, in line with our objective to evaluate the predictive ability of the different value measurement methods, an estimation approach that ensures optimal prediction accuracy was desirable (Hair et al. 2011). Second, PLS path modeling allowed us to estimate measurement models that include both formative and reflective indicators. This feature is particularly relevant, as the literature indicates that value measurement models include both types of measures (Ruiz et al. 2008). To assess the statistical significance of the parameter estimates, we constructed percentile bootstrap confidence intervals based on 5,000 samples (Hair et al. 2011; Preacher and Hayes 2008).

\section{Measurement model structures}

Dodds et al.'s (1991) approach In keeping with its original scale development process and further applications in the literature, we specified Dodds et al.'s (1991) measurement scale as a first-order reflective measurement model.

Gale's (1994) approach With respect to the Customer Value Analysis suggested by Gale (1994), we started from its basic premise that customer value equals the difference between a weighted quality score (market-perceived quality) and a weighted price score (market-perceived price). Both scores were determined by multiplying the relative performance score (relative price) for each quality (price) attribute by its normalized weight and summing these weighted scores over the relevant quality (price) attributes. Subsequently, following the rationale of Jarvis et al. (2003), we used this marketperceived quality score and market-perceived price score as formative indicators of the customer value construct.

Woodruff and Gardial's (1996) approach Concerning the customer value measurement approach recommended by Woodruff and Gardial (1996), it is important to distinguish between the first- and second-order constructs. According to research by Ruiz et al. (2008) and Lin et al. (2005), the benefit and sacrifice components (first-order constructs) associated with this approach should be considered formative components of customer value, because customers make an explicit mental tradeoff between these components to arrive at an overall value perception (second-order construct). The two first-order constructs - benefits and sacrifices - were modeled according to the guidelines developed by Jarvis et al. (2003). Specifically, the benefits construct consists of diverse positive consequences mentioned during the laddering interviews and, hence, is modeled formatively. Alternatively, the sacrifice construct is measured by two reflective indicators reflecting the monetary consequences of the product. To model customer value as a second-order construct, we used the two-stage approach (Reinartz et al. 2004; Ringle et al. 2012) wherein, in the first stage, the latent variable scores were estimated without the second-order construct (customer value) present but with all of the first-order constructs (benefits and sacrifices) in the model. In the second stage, the latent variable scores of the first-order factors (benefits and sacrifices) were used as indicators of the second-order construct (customer value) in a separate higher-order PLS model.

Holbrook's (1999) approach Regarding the value typology specified by Holbrook (1999), customer value can be considered a higher-order construct consisting of multiple components (Gallarza and Gil-Saura 2006; Sánchez-Fernández et al. 2009). Thus, each of Holbrook's (1999) value types can be considered a first-order construct measured either by reflective or formative indicators. In our case, because the different value types are not interchangeable and not necessarily correlated, and the direction of causality is from each of the value types to the overall customer value construct, these value types should be considered formative components of customer value (Jarvis et al. 2003). To model customer value as a second-order construct, we again used the two-stage approach described above (Reinartz et al. 2004).

\section{Results}

Tables 2, 3, 4 and 5 present the correlations, means, and standard deviations for the value measures (or their dimensions), cumulative satisfaction, repurchase intentions, and word of mouth across each of the settings and each of the methods.

Measurement model: psychometric properties

All relevant psychometric properties of the constructs under study are presented in Appendices A and B. Our analyses confirmed favorable psychometric properties for the four methods in the four different settings, with the exception of Dodds et al.'s (1991) approach. In particular, the results (see Appendix B) show that the scale suggested by Dodds et al. (1991) is not unidimensional for the two think settings (i.e., toothpaste and DVD players). More specifically, in these settings, the eigenvalues of the construct's inter-item correlation matrix reveal the existence of more than one construct underlying the five items. Since these items are intended to be alternative indicators of the same underlying construct (i.e., value), this violates one of the most critical and basic assumptions of measurement theory (Gerbing and Anderson 1988). 
Table 2 Summary of correlations, means and standard deviations for Dodds et al.'s method

\begin{tabular}{|c|c|c|c|c|c|c|c|c|c|c|c|c|c|}
\hline \multicolumn{7}{|l|}{ Think } & \multicolumn{7}{|l|}{ Feel } \\
\hline & VAL & SAT & REP & WOM & $\mathrm{M}$ & $\mathrm{SD}$ & & VAL & SAT & REP & WOM & $\mathrm{M}$ & $\mathrm{SD}$ \\
\hline VAL & - & $.48 * *$ & $.47 * *$ & $.45^{* *}$ & 6.65 & 1.28 & VAL & - & $.32 * *$ & $.27 * *$ & $.35 * *$ & 6.24 & 1.46 \\
\hline SAT & $.34 * *$ & - & $.52 * *$ & $.56^{* *}$ & 7.78 & 1.64 & SAT & $.41 * *$ & - & $.64 * *$ & $.50 * *$ & 8.26 & 1.23 \\
\hline REP & $.33 * *$ & $.43 * *$ & - & $.73 * *$ & 6.41 & 1.65 & REP & $.33 * *$ & $.55^{* *}$ & - & $.58 * *$ & 7.29 & 1.53 \\
\hline WOM & $.42 * *$ & $.38 * *$ & $.52 * *$ & - & 6.26 & 1.75 & WOM & $.34 * *$ & $.57 * *$ & $.55^{* *}$ & - & 6.84 & 1.48 \\
\hline $\mathrm{M}$ & 5.89 & 7.91 & 7.14 & 6.07 & & & $\mathrm{M}$ & 5.56 & 8.38 & 7.60 & 6.44 & & \\
\hline SD & 1.06 & 1.42 & 1.56 & 1.81 & & & SD & 1.59 & 1.24 & 1.38 & 1.95 & & \\
\hline
\end{tabular}

Correlations for high (low) involvement offerings are presented above (below) the diagonal. Means and standard deviations for high (low) involvement offerings are presented in the vertical columns (horizontal rows)

$V A L$ value, $S A T$ satisfaction, $R E P$ repurchase intentions, $W O M$ word of mouth

${ }^{*} p<.05 * * p<.01$

Because of the lack of favorable psychometric properties for the Dodds et al. (1991) scale, we did not use this measurement method in further analyses (e.g., to compare predictive ability) in the toothpaste and DVD player settings.

Overall, with the exception of the Dodds et al. (1991) method for the two think offerings, the four different methods are capable of assessing customer value perceptions in a reliable and valid manner across different settings.

Structural model: predictive ability

The performance of the four customer value measurement methods with regard to their predictive ability of customer satisfaction, repurchase intentions, and word of mouth, was evaluated by means of the multiple correlation coefficient $R$. The $\mathrm{R}$ coefficient is defined as the correlation between the actual (y) and the predicted value ( $\hat{y})$ of the dependent variable. As each respondent filled out a questionnaire containing only one of the different value measurement methods under study, testing $\mathrm{H} 1$ and $\mathrm{H} 2$ regarding the methods' predictive validity boils down to assessing whether the relevant independent sample correlation coefficients are statistically equal. In cases where the null hypothesis of equal correlation coefficients was rejected, post-hoc comparison tests as proposed by Zar (1996) were conducted.

Table 6 displays the R-values for each of the settings as well as a pairwise comparison between these R-values. The $\mathrm{R}^{2}$-values (i.e., the coefficients of determination) can be found in parentheses. All R-values ( $\mathrm{R}^{2}$-values) are significantly different from zero, meaning that all four value measurement methods are capable of explaining variance in cumulative satisfaction, repurchase intentions, and word of mouth. Note that, for think offerings (i.e., toothpaste and DVD player), the $\mathrm{R}$ - and $\mathrm{R}^{2}$-values are not calculated for the Dodds et al. (1991) approach because the scale did not possess favorable psychometric properties for these settings.

Although in some instances, the one-dimensional approach of Dodds et al. (1991) performed equally well as the multidimensional methods, it is important to note that it never outperformed them. Thus, in general, H1 is supported.

Table 3 Summary of correlations, means and standard deviations for Gale's method

\begin{tabular}{|c|c|c|c|c|c|c|c|c|c|c|c|c|c|c|c|}
\hline \multicolumn{8}{|l|}{ Think } & \multicolumn{8}{|l|}{ Feel } \\
\hline & MPQ & MPP & SAT & REP & WOM & M & SD & & MPQ & MPP & SAT & REP & WOM & M & SD \\
\hline MPQ & - & $-.35^{* *}$ & $.43 * *$ & $.51 * *$ & $.58^{* *}$ & 6.15 & 1.12 & MPQ & - & $-.36 * *$ & $.45^{* *}$ & $.45 * *$ & $.46^{* *}$ & 6.78 & 1.26 \\
\hline MPP & $-.44 * *$ & - & -.13 & $-.14 *$ & $-.18^{* *}$ & 3.88 & 1.51 & MPP & $-.15^{*}$ & - & $-.15^{*}$ & -.14 & -.12 & 4.08 & 1.69 \\
\hline SAT & $.46^{* *}$ & $-.17 *$ & - & $.59 * *$ & $.69^{* *}$ & 7.80 & 1.71 & SAT & $.37 * *$ & $-.18 *$ & - & $.65^{* *}$ & $.55^{* *}$ & 8.46 & 1.28 \\
\hline REP & $.37^{* *}$ & .00 & $.59 * *$ & - & $.62 * *$ & 6.30 & 1.55 & REP & $.35^{* *}$ & -.05 & $.46^{* *}$ & - & $.57 * *$ & 7.44 & 1.43 \\
\hline WOM & $.49 * *$ & $-.15^{*}$ & $.54 * *$ & $.61^{* *}$ & - & 6.25 & 1.90 & WOM & $.49^{* *}$ & -.07 & $.47 * *$ & $.50 * *$ & - & 6.90 & 1.57 \\
\hline M & 6.28 & 4.21 & 8.31 & 7.24 & 6.30 & & & M & 6.61 & 4.33 & 8.69 & 7.79 & 6.78 & & \\
\hline SD & 1.14 & 1.32 & 1.27 & 1.65 & 1.96 & & & SD & 1.06 & 1.76 & 1.00 & 1.23 & 1.62 & & \\
\hline
\end{tabular}

Correlations for high (low) involvement offerings are presented above (below) the diagonal. Means and standard deviations for high (low) involvement offerings are presented in the vertical columns (horizontal rows)

$M P Q$ market-perceived quality, MPP market-perceived price, SAT satisfaction, REP repurchase intentions, WOM word of mouth

${ }^{*} p<.05 * * p<.01$ 
Table 4 Summary of correlations, means and standard deviations for Woodruff and Gardial's method

\begin{tabular}{|c|c|c|c|c|c|c|c|c|c|c|c|c|c|c|c|}
\hline \multicolumn{8}{|l|}{ Think } & \multicolumn{8}{|l|}{ Feel } \\
\hline & BEN & SAC & SAT & REP & WOM & $\mathrm{M}$ & $\mathrm{SD}$ & & BEN & SAC & SAT & REP & WOM & $\mathrm{M}$ & SD \\
\hline BEN & - & $-.22 * *$ & $.65 * *$ & $.48 * *$ & $.70 * *$ & 6.58 & 1.08 & BEN & - & $-.34 * *$ & $.59 * *$ & $.50 * *$ & $.70 * *$ & 7.16 & 1.25 \\
\hline SAC & $-.33 * *$ & - & $-.14 *$ & $-.17 *$ & $-.15^{*}$ & 4.00 & 1.74 & SAC & $-.27 * *$ & - & $-.24 * *$ & $-.17 *$ & $-.32 * *$ & 4.19 & 2.33 \\
\hline SAT & $.50 * *$ & $-.34 * *$ & - & $.55^{* *}$ & $.68^{* *}$ & 7.70 & 1.69 & SAT & $.61^{* *}$ & -.02 & - & $.53 * *$ & $.54 * *$ & 8.35 & 1.26 \\
\hline REP & $.43 * *$ & -.01 & $.51 * *$ & - & $.65^{* *}$ & 6.28 & 1.66 & REP & $.52 * *$ & -.06 & $.60 * *$ & - & $.59 * *$ & 7.40 & 1.44 \\
\hline WOM & $.51 * *$ & $-.18 * *$ & $.46^{* *}$ & $.55 * *$ & - & 6.43 & 1.81 & WOM & $.50 * *$ & $-.19 * *$ & $.56^{* *}$ & $.53 * *$ & - & 7.03 & 1.40 \\
\hline M & 6.28 & 4.73 & 7.96 & 7.07 & 5.98 & & & M & 6.19 & 5.27 & 8.16 & 7.50 & 6.33 & & \\
\hline SD & 1.26 & 1.87 & 1.30 & 1.61 & 1.81 & & & $\mathrm{SD}$ & 1.10 & 2.19 & 1.22 & 1.35 & 1.79 & & \\
\hline
\end{tabular}

Correlations for high (low) involvement offerings are presented above (below) the diagonal. Means and standard deviations for high (low) involvement offerings are presented in the vertical columns (horizontal rows)

$B E N$ benefits, $S A C$ sacrifices, $S A T$ satisfaction, $R E P$ repurchase intentions, WOM word of mouth

$* p<.05 * * p<.01$

Second, it is interesting to note that the best-performing methods - those of Woodruff and Gardial (1996) and Holbrook (1999) - assess benefits and sacrifices at the consequence level, which supports H2.
In aggregate, these results indicate that, from a strictly methodological point of view, the methods proposed by Woodruff and Gardial (1996) and Holbrook (1999) are the best choices to measure value. We note, however, that although both

Table 5 Summary of correlations, means and standard deviations for Holbrook's method

\begin{tabular}{|c|c|c|c|c|c|c|c|c|c|c|}
\hline & AEST & EFF & EXC & PLAY & SOC & SAT & REP & WOM & M & $\mathrm{SD}$ \\
\hline \multicolumn{11}{|l|}{ Think } \\
\hline AEST & - & .02 & $.47 * *$ & $.55^{* *}$ & $.25 * *$ & $.34 * *$ & $.23 * *$ & $.33 * *$ & 5.36 & 1.90 \\
\hline EFF & .10 & - & .08 & -.12 & $-.33 * *$ & $.24 * *$ & $.22 * *$ & .11 & 6.90 & 1.31 \\
\hline EXC & $.51^{* *}$ & $.18^{* *}$ & - & $.35^{* *}$ & .09 & $.54 * *$ & $.47 * *$ & $.53 * *$ & 5.96 & 1.46 \\
\hline PLAY & $.69 * *$ & -.05 & $.30 * *$ & - & $.44^{* *}$ & $.14^{*}$ & .02 & $.21 * *$ & 4.46 & 1.69 \\
\hline SOC & $.49 * *$ & $-.27 * *$ & .04 & $.57 * *$ & - & -.08 & -.13 & -.01 & 2.06 & 1.59 \\
\hline SAT & $.41 * *$ & $.29 * *$ & $.70 * *$ & $.23 * *$ & .03 & - & $.54 * *$ & $.56^{* *}$ & 7.94 & 1.34 \\
\hline REP & $.36^{* *}$ & $.23 * *$ & $.73 * *$ & $.16^{*}$ & -.09 & $.67 * *$ & - & $.63 * *$ & 6.15 & 1.49 \\
\hline WOM & $.52 * *$ & .10 & $.69 * *$ & $.42 * *$ & $.23 * *$ & $.59 * *$ & $.59^{* *}$ & - & 6.19 & 1.69 \\
\hline M & 5.61 & 6.96 & 6.67 & 4.30 & 2.71 & 8.01 & 7.18 & 6.10 & & \\
\hline SD & 1.79 & 1.25 & 1.47 & 2.14 & 1.90 & 1.73 & 1.70 & 1.82 & & \\
\hline \multicolumn{11}{|l|}{ Feel } \\
\hline AEST & - & $.16^{*}$ & $.60 * *$ & $.56^{* *}$ & $.26^{* *}$ & $.49 * *$ & $.46^{* *}$ & $.52 * *$ & 6.52 & 1.67 \\
\hline EFF & $-.19 * *$ & - & .05 & -.06 & $-.35 * *$ & $.20 * *$ & $.21 * *$ & .06 & 6.97 & 1.36 \\
\hline EXC & $.22 * *$ & -.12 & - & $.40 * *$ & $.23^{* *}$ & $.67 * *$ & $.57 * *$ & $.52 * *$ & 6.72 & 1.36 \\
\hline PLAY & $.52 * *$ & $-.17 *$ & $.35^{* *}$ & - & $.48^{* *}$ & $.31^{* *}$ & $.30 * *$ & $.43 * *$ & 5.60 & 1.92 \\
\hline SOC & $.59 * *$ & $-.33 * *$ & .09 & $.40 * *$ & - & .07 & .04 & $.26^{* *}$ & 3.27 & 1.97 \\
\hline SAT & .13 & .02 & $.66^{* *}$ & $.25^{* *}$ & -.01 & - & $.76^{* *}$ & $.58 * *$ & 8.21 & 1.21 \\
\hline REP & -.04 & -.07 & $.53^{* *}$ & $.16^{*}$ & -.11 & $.55^{* *}$ & - & $.67 * *$ & 7.39 & 1.50 \\
\hline WOM & $.24 * *$ & -.03 & $.51^{* *}$ & $.42 * *$ & $.15^{*}$ & $.59 * *$ & $.61^{* *}$ & - & 6.81 & 1.56 \\
\hline M & 2.59 & 6.39 & 6.82 & 4.29 & 2.14 & 8.38 & 7.51 & 6.08 & & \\
\hline SD & 1.93 & 1.45 & 1.65 & 2.13 & 1.72 & 1.36 & 1.58 & 2.29 & & \\
\hline
\end{tabular}

Correlations for high (low) involvement offerings are presented above (below) the diagonal. Means and standard deviations for high (low) involvement offerings are presented in the vertical columns (horizontal rows)

AEST aesthetics, EFF efficiency, EXC excellence, PLAY play, SOC social value, SAT satisfaction, REP repurchase intentions, WOM word of mouth $* p<.05 * * p<.01$ 
Table 6 Comparison between the coefficients of determination

\begin{tabular}{|c|c|c|c|c|c|c|c|c|c|c|c|c|c|c|c|}
\hline & \multicolumn{5}{|c|}{ Satisfaction } & \multicolumn{5}{|c|}{ Word of mouth } & \multicolumn{5}{|c|}{ Repurchase Intention } \\
\hline & & $\mathrm{D}$ & $\mathrm{G}$ & W & $\mathrm{H}$ & & $\mathrm{D}$ & G & W & $\mathrm{H}$ & & $\mathrm{D}$ & G & $\mathrm{W}$ & $\mathrm{H}$ \\
\hline Toothpaste & $\mathrm{D}$ & & & & & $\mathrm{D}$ & & & & & $\mathrm{D}$ & & & & \\
\hline \multirow[t]{4}{*}{ Think - Low involv } & $\mathrm{G}$ & & $.46(.21)$ & & $* *$ & G & & $.61(.37)$ & & $*$ & G & & $.62(.38)$ & & $* *$ \\
\hline & $\mathrm{W}$ & & & $.56(.31)$ & $* *$ & $\mathrm{~W}$ & & & $.63(.40)$ & & $\mathrm{W}$ & & & $.62(.38)$ & $* *$ \\
\hline & $\mathrm{H}$ & & $* *$ & $* *$ & $.71(.50)$ & $\mathrm{H}$ & & $*$ & & $.72(.52)$ & $\mathrm{H}$ & & $* *$ & $* *$ & $.78(.61)$ \\
\hline & & $\mathrm{D}$ & G & $\mathrm{W}$ & $\mathrm{H}$ & & $\mathrm{D}$ & G & W & $\mathrm{H}$ & & $\mathrm{D}$ & G & W & $\mathrm{H}$ \\
\hline Soft drink & $\mathrm{D}$ & $.47(.22)$ & & $* *$ & $* *$ & $\mathrm{D}$ & $.60(.36)$ & & & & $\mathrm{D}$ & $.63(.39)$ & & & \\
\hline \multirow[t]{4}{*}{ Feel - Low involv } & $\mathrm{G}$ & & $.38(.14)$ & $* *$ & $* *$ & $\mathrm{G}$ & & $.58(.33)$ & & & $\mathrm{G}$ & & $.55(.31)$ & & \\
\hline & $\mathrm{W}$ & $* *$ & $* *$ & $.74(.55)$ & & $\mathrm{W}$ & & & $.59(.35)$ & & $\mathrm{W}$ & & & $.67(.45)$ & \\
\hline & $\mathrm{H}$ & $* *$ & $* *$ & & $.67(.45)$ & $\mathrm{H}$ & & & & $.62(.39)$ & $\mathrm{H}$ & & & & $.64(.40)$ \\
\hline & & $\mathrm{D}$ & $\mathrm{G}$ & W & $\mathrm{H}$ & & $\mathrm{D}$ & G & W & $\mathrm{H}$ & & $\mathrm{D}$ & G & W & $\mathrm{H}$ \\
\hline DVD player & $\mathrm{D}$ & & & & & $\mathrm{D}$ & & & & & $\mathrm{D}$ & & & & \\
\hline \multirow[t]{4}{*}{ Think - High involv } & G & & $.43(.19)$ & $* *$ & $* *$ & G & & $.76(.58)$ & & $* *$ & G & & $.69(.48)$ & & \\
\hline & W & & $* *$ & $.73(.54)$ & $*$ & W & & & $.76(.58)$ & $* *$ & $\mathrm{~W}$ & & & $.61(.38)$ & \\
\hline & $\mathrm{H}$ & & $* *$ & $*$ & $.62(.38)$ & $\mathrm{H}$ & & $* *$ & $* *$ & $.62(.38)$ & $\mathrm{H}$ & & & & $.61(.37)$ \\
\hline & & $\mathrm{D}$ & G & W & $\mathrm{H}$ & & $\mathrm{D}$ & G & W & $\mathrm{H}$ & & $\mathrm{D}$ & G & W & $\mathrm{H}$ \\
\hline Day cream & $\mathrm{D}$ & $.42(.18)$ & & $* *$ & $* *$ & $\mathrm{D}$ & $.56(.32)$ & & $* *$ & & $\mathrm{D}$ & $.65(.43)$ & & & $*$ \\
\hline \multirow[t]{3}{*}{ Feel - High involv } & G & & $.45(.20)$ & $*$ & $* *$ & G & & $.60(.36)$ & $*$ & & G & & $.73(.53)$ & & \\
\hline & $\mathrm{W}$ & $* *$ & * & $.62(.38)$ & & W & $* *$ & $*$ & $.73(.54)$ & & $\mathrm{W}$ & & & $.67(.45)$ & \\
\hline & $\mathrm{H}$ & $* *$ & $* *$ & & $.68(.47)$ & $\mathrm{H}$ & & & & $.64(.41)$ & $\mathrm{H}$ & $*$ & & & $.77(.60)$ \\
\hline
\end{tabular}

This table displays the R-values with the $\mathrm{R}^{2}$-values in parenthesis

$D$ Dodds et al., $G$ Gale, $W$ Woodruff and Gardial, $H$ Holbrook

$* p<.10 * * p<.05$

approaches perform well in a general sense and for feel products, this is not the case for think products. Regarding lowinvolvement think products, the method of Holbrook (1999) is the safest choice, as its predictive ability is at least equal to that of Woodruff and Gardial's (1996) approach, whereas, for highinvolvement think offerings, the opposite holds. Here, the method of Woodruff and Gardial (1996) is preferred, as its performance is at least equal to that of Holbrook's (1999) method.

\section{Practicality}

Dodds et al.'s (1991) approach can be used to measure value in the case of feel products because it is a straightforward and simple method, and it consists of only five items. Furthermore, it can be used in these settings without any major adjustments. As such, it is easy to incorporate in a questionnaire, has only a limited impact on questionnaire length, and requires little effort on behalf of the respondent.

Gale's (1994) method requires a combination of performance and importance weights, thereby increasing questionnaire length and respondents' effort substantially. From the researcher's perspective, the practicality of Gale's (1994) method depends on whether the relevant attributes are known beforehand. When these attributes are unknown, the researcher needs to invest time and effort in conducting interviews to generate them.
Because of its focus on the consequences instead of the attributes, interviews are almost always required to generate items for Woodruff and Gardial's (1996) method. Regarding questionnaire length, the scales we used for this approach consisted of $11-16$ items, which is two to three times more than the shortest scale, i.e., that of Dodds et al. (1991).

Holbrook's (1999) approach consists of various value types. Some of these value types have an existing scale; for example, to measure social value one can use the scale of Sweeney and Soutar (2001). However, for other value types, interviews could be necessary to generate items. Furthermore, the use of various value types, each having its own scale, results in a great number of items, thus negatively impacting questionnaire length.

To compare the measurement methods with regard to the effect of questionnaire length, we conducted an additional study in which we assessed response times and asked some questions about the perceived time and effort required to fill out the questionnaire (the items are presented in Table 7). We used toothpaste as the setting for this study and opted for a betweensubjects design to avoid carry-over effects among the different value measurement approaches. The sample consisted of 310 undergraduate students at a large American state university. The results of this study are presented in Table 7 . With regard to the objective time required to fill out the questionnaire, a significant 
difference was found between the various methods $(F=35.315$; $p<.001)$. Pairwise analyses show that the scale used by Dodds et al. (1991) required significantly less time to complete than the other methods. However, regarding the respondent's perceptions of time and effort, no significant differences were found between the four methods (see $F$-values in Table 7). Thus, although Dodds et al. (1991) method has the least items and requires the least time to complete, this feature is not reflected in the respondent's perceived effort and time.

\section{Actionability}

As a final comparison, we examine the relative actionability of the four measurement approaches. Actionability refers to the degree to which the methods yield information that is relevant for diagnostic purposes or easily translated into actionable strategies. Methods that prioritize attributes or consequences therefore would be more actionable than methods that do not. As an example, a problem with Dodds et al.'s (1991) approach is that although a firm may know its overall value score, no specific direction is given in terms of how it can be improved (Petrick 2002). Thus, while the Dodds et al. (1991) measure scored high in practicality, there is a tradeoff in that it is low in actionability. Furthermore, this method had unfavorable psychometric properties in the case of think offerings and, hence, should only be used for feel products.

Gale's (1994) method, on the other hand, clearly identifies directions for improvement. Since it is based on a combination of importance and relative performance, it is fairly easy to discern a product's strengths and weaknesses (Gale 1994). Furthermore, Gale (1994) suggests various practical guidelines and tools to analyze the data, such as a customer value map and a head-to-head chart.

However, several authors (e.g., MacDonald et al. 2011; Woodruff 1997; Woodruff and Gardial 1996) have indicated that only focusing on attributes (e.g., Gale's approach) is not enough. "A substantive, radical, and strategically sustainable advantage is more likely to result when organizations step back from a narrow focus on attribute improvement and consider the broader issues of consequence and value delivery" (Woodruff and Gardial 1996, p. 80). What customers really desire are not the attributes but the consequences resulting from product use (Lusch and Vargo 2006), which favors the methods of Woodruff and Gardial (1996) and Holbrook (1999). Aside from this strength of being consequence-based, several authors (e.g., Bevan and Murphy 2001; Smith 1999) note that Holbrook's typology scores high in terms of actionability because it offers a complete, clear, efficient, easily comprehensible and intuitively appealing model for researchers and practitioners alike.

\section{Discussion}

This study was aimed at comparing four commonly used customer value measurement methods (i.e., Dodds et al.

Table 7 Results regarding time and effort

\begin{tabular}{|c|c|c|c|c|c|c|c|c|c|}
\hline & \multicolumn{2}{|c|}{$\begin{array}{l}\text { Dodds et al.'s } \\
\text { method } \\
n=81\end{array}$} & \multicolumn{2}{|c|}{$\begin{array}{l}\text { Gale's } \\
\text { method } \\
n=80\end{array}$} & \multicolumn{2}{|c|}{$\begin{array}{l}\text { Woodruff and } \\
\text { Gardial's method } \\
n=68\end{array}$} & \multicolumn{2}{|c|}{$\begin{array}{l}\text { Holbrook's } \\
\text { method } \\
n=81\end{array}$} & \multirow{2}{*}{$\begin{array}{l}\text { Results } \\
\text { ANOVA } \\
\text { F ( } p \text {-value) }\end{array}$} \\
\hline & M & SD & $\mathrm{M}$ & SD & M & SD & $\mathrm{M}$ & SD & \\
\hline Objective time (in seconds) & 27.02 & 15.30 & 76.14 & 47.38 & 78.60 & 41.16 & 81.56 & 44.31 & $35.32(.00)$ \\
\hline \multicolumn{10}{|l|}{ Perception of time (9-point scales) } \\
\hline $\begin{array}{l}\text { How much time was required from you } \\
\text { to fill out this survey? very little } \\
\text { time - a great deal of time }\end{array}$ & 1.95 & 1.26 & 2.10 & 1.38 & 1.96 & 1.41 & 2.05 & 1.45 & $.22(.88)$ \\
\hline $\begin{array}{l}\text { The time required to fill out this survey } \\
\text { is... very low - very high }\end{array}$ & 1.89 & 1.23 & 2.16 & 1.38 & 2.00 & 1.41 & 2.09 & 1.48 & $.58(.63)$ \\
\hline \multicolumn{10}{|l|}{ Perception of effort (9-point scales) } \\
\hline It was difficult for me to fill out the survey. & 1.95 & 1.80 & 2.30 & 1.80 & 2.19 & 1.93 & 2.64 & 2.35 & $1.69(.17)$ \\
\hline $\begin{array}{l}\text { I had to concentrate a lot while filling } \\
\text { out the survey. }\end{array}$ & 1.96 & 1.74 & 2.51 & 1.97 & 2.35 & 1.98 & 2.46 & 2.19 & $1.27(.28)$ \\
\hline $\begin{array}{l}\text { I had to think very hard about } \\
\text { answering some questions. }\end{array}$ & 2.07 & 1.92 & 2.43 & 1.73 & 2.26 & 1.85 & 2.35 & 1.96 & $.52(.67)$ \\
\hline $\begin{array}{l}\text { How much effort was required from you } \\
\text { to fill out this survey? very little } \\
\text { effort - a great deal of effort }\end{array}$ & 2.15 & 1.58 & 2.71 & 1.78 & 2.41 & 1.93 & 2.35 & 1.59 & $1.49(.22)$ \\
\hline $\begin{array}{l}\text { The effort required to fill out this survey } \\
\text { is... very low - very high }\end{array}$ & 1.88 & 1.21 & 2.38 & 1.55 & 2.29 & 1.66 & 2.10 & 1.45 & $1.82(.14)$ \\
\hline
\end{tabular}


1991; Gale 1994; Holbrook 1999; Woodruff and Gardial 1996) with regard to two quantitative (psychometric properties and predictive ability) and two subjective (practicality and actionability) topics. A summary of the results can be found in Table 8.

Our findings show that all methods possess favorable psychometric properties. The only notable exception concerns the method of Dodds et al. (1991), which displays poor psychometric properties for both think offerings (i.e., the toothpaste and DVD player settings). Hence, this method should not be used in this context. In terms of predictive ability, our analyses show that multidimensional, consequence-based methods, such as the Woodruff and Gardial (1996) and Holbrook (1999) methods, are the best choices. This finding is in line with the observation of Sánchez-Fernández and Iniesta-Bonillo (2007) who state that multi-dimensional approaches are needed to adequately capture the complexity of consumers' value perceptions. Likewise, our finding fits the concept of 'value-in-use', implying that value is fundamentally derived and determined in use (i.e., consequences) rather than in exchange (i.e., attributes)
(Vargo et al. 2008). In choosing between the methods developed by Woodruff and Gardial (1996) and the one developed by Holbrook (1999), the type of setting may offer some insight. For low involvement, think offerings, the method of Holbrook (1999) has the highest predictive ability. In contrast, for high involvement, think offerings, the approach of Woodruff and Gardial (1996) performs best. For feel offerings, the two multidimensional consequence-based methods perform equally well, regardless of the level of involvement.

Given that the main advantage of the Dodds et al. (1991) approach is its brevity and adaptability, it may be an optimal approach to use when practicality is an important criterion. Likewise, the Dodds et al. (1991) approach may be well suited for studies where perceived value is positioned as one element in an extensive nomological network. However, whereas this method has the least items and requires the least time to complete, it should be noted that this is not reflected in the respondent's perceived effort and time.

If the research focus is on obtaining actionable results or uncovering strategic initiatives to improve customer value, the approach of Dodds et al. (1991) is not desirable. The choice

Table 8 Comparison between value measurement methods

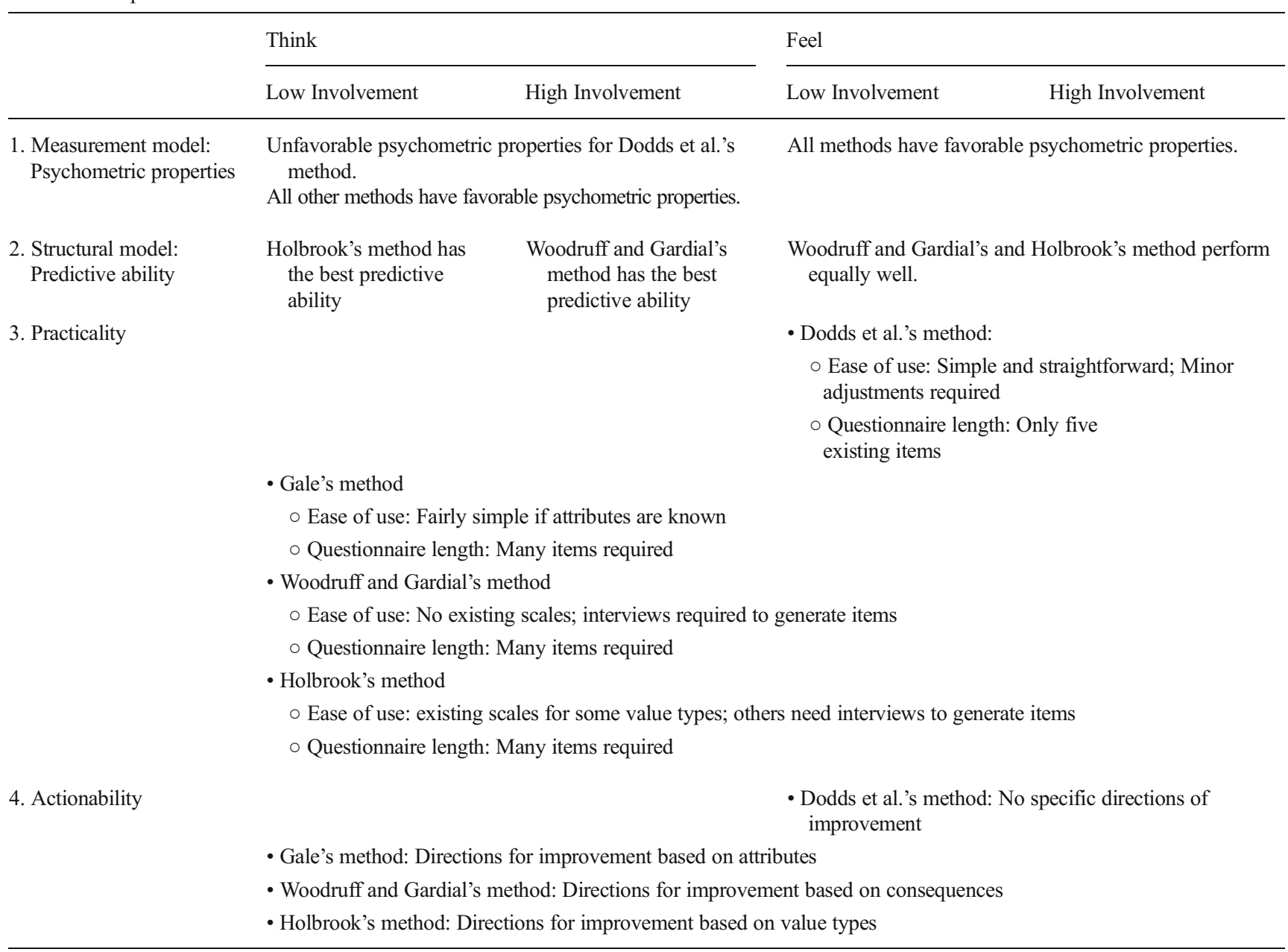


between the methods of Gale (1994), Woodruff and Gardial (1996) and Holbrook (1999) may be guided by attributes or consequences. As it can be expected that firms may know the attributes associated with its own products, Gale's (1994) approach seems to be a good choice for measuring customer value in practice. However, if the company wants to look beyond the mere attributes of its products and it intends to come up with creative and innovative solutions for customer needs, it is better to focus on the consequences (MacDonald et al. 2011; Woodruff 1997) and therefore, the methods of Woodruff and Gardial (1996) and Holbrook (1999) should be used. In the subsequent choice between the methods of Woodruff and Gardial (1996) and Holbrook (1999), it is important to note two characteristics of the Holbrook (1999) conceptualization. First, an advantage of Holbrook's (1999) method is its classification framework that could be very helpful in structuring the different value types in an understandable and intuitively appealing way. Second, existing scales are available for some of Holbrook's value types, thereby limiting the time and effort needed to design a suitable measurement instrument.
To summarize our findings and provide guidance to those interested in measuring customer value, we constructed the prescriptive flowchart presented in Fig. 2. This flowchart aims to provide direction when choosing an adequate method based on the specific context.

\section{Limitations and future research}

Although this study contributes to our understanding of customer value and its measurement, several limitations and further research suggestions deserve to be mentioned. First, other products with more extreme levels of high/low involvement or think/feel could be used. Although the four settings selected for this study differed significantly in terms of involvement (high/low) and type of offering (think/feel), future work could replicate our findings in, perhaps, more extreme settings. Also, the applicability across different settings could be explored along other dimensions. One dimension for further testing might be the level of product knowledge, which has been shown to affect customers'
Fig. 2 Guidelines for choosing a customer value measurement method

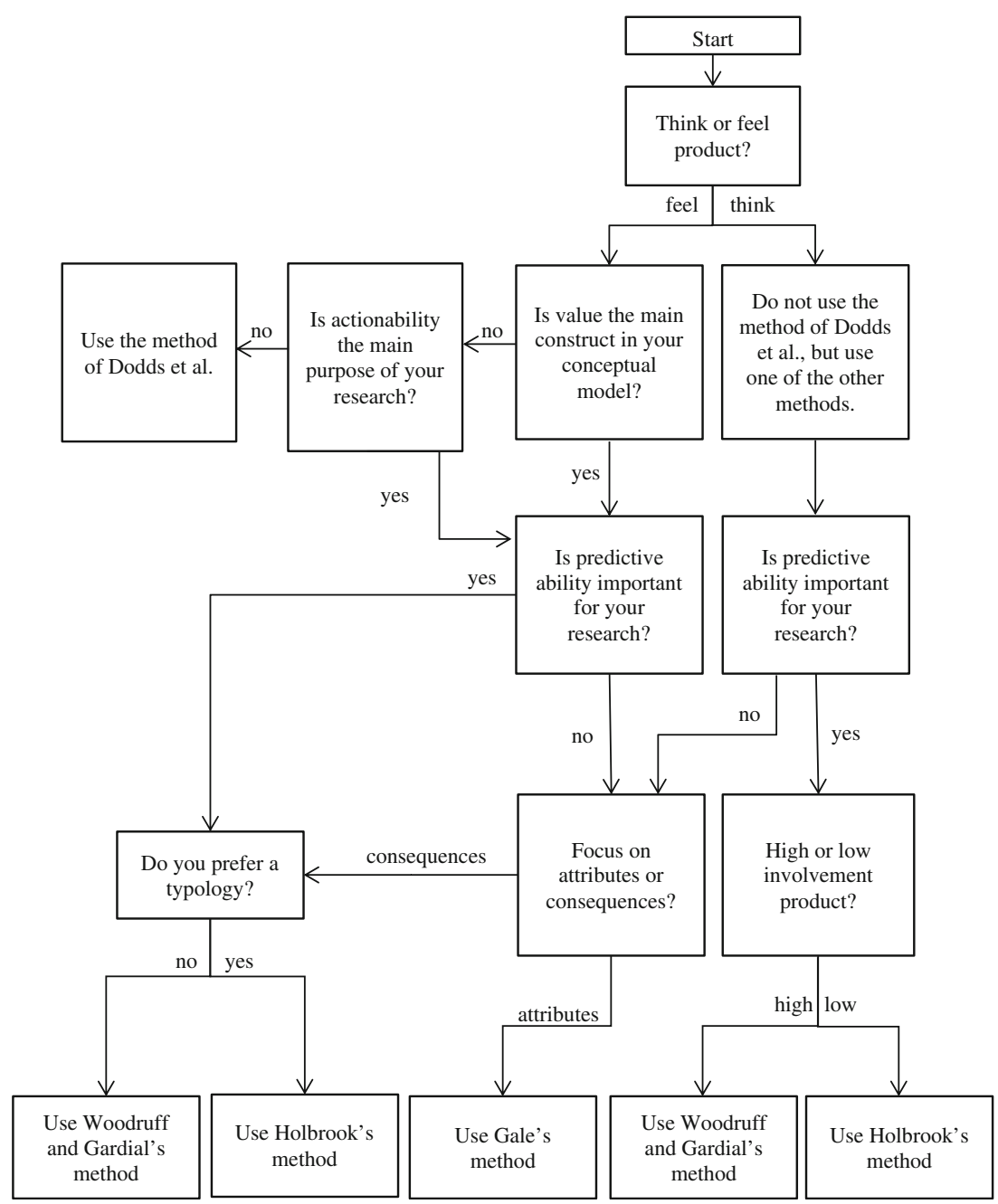


means-end associations (e.g., Graeff 1997). In addition, future work could replicate our findings in less tangible settings.

Second, we used customer satisfaction, repurchase intentions, and word of mouth as criterion variables to assess predictive ability. Although we deliberately chose to operationalize these outcome variables in a way that is consistent with the majority of existing academic research, we are aware that alternative approaches to measure the three outcome variables might yield different results.

Third, measures of actual behavior, rather than behavioral intentions, could enhance the soundness of this study. Unfortunately, such behavioral data are often difficult and expensive to obtain. In addition, it should be noted that, although a significant positive association between intention and behavior exists, the conversion of (re)purchase intentions into (re)purchase behavior may be moderated by various factors (e.g., Seiders et al. 2005).

Fourth, recent research (i.e., Grönroos 2011; Grönroos and Ravald 2011) emphasizes the importance of value co-creation for contemporary marketing literature as well as practice. Hence, future research should consider the value co-creating opportunities of the firm as well as the consequences of this value co-creation for the customer. This value co-creation can influence how value could and should be measured. For example, when value is co-created, there could be other value types that come into play during direct interactions with the firm. Along these lines, an opportunity for further research is the difference, and maybe also the interaction, between valuein-use and co-created value. Are value-in-use and co-created value complementary or substitutable concepts? Do they strengthen each other? Are there other value types that come into play when value is co-created? These and other, similar questions are worthy topics for future research.

Finally, a fruitful avenue for further research is to investigate the linkages between the attributes and consequences as mentioned in Woodruff and Gardial's (1996) Value Hierarchy. Although these authors indicate that "value is a trade-off between the positive and negative consequences of product use as perceived by the customer" (Woodruff and Gardial 1996, p. 57), they also indicate that it is important to understand the linkages between attributes, consequences and desired end-states. The focus of this research was on the assessment of four common value measures and therefore these linkages were not included in the present study. Future research could examine these linkages in further detail and provide additional insights into the way customer value is created.

Despite these limitations, this study provides a more comprehensive, in-depth understanding of customer value as well as an important tool for managers, since "making customer value strategies work begins with an actionable understanding of the concept itself" (Woodruff 1997, p. 141).

Acknowledgments The authors wish to thank Wim Janssens for his helpful comments on early drafts of this article. The authors thank the Research Foundation - Flanders (FWO Vlaanderen) for a doctoral fellowship.

Funding This work was supported by the Marketing Science Institute [grant \#4-1668].

\section{Appendix A}

\begin{tabular}{lllll}
\hline & Toothpaste & Soft drink & DVD player & Day cream \\
\hline Attributes & Quality attributes & Quality attributes & Quality attributes & Quality attributes \\
& Good taste & Good taste & Price-quality relationship & Caring \\
& Whitening & Amount of sparkles & Look (e.g., design, color, size) & A well-known brand \\
& Against teeth cavities & Amount of sugar & Quality & Quality \\
& User-friendly packaging & Nice feeling in mouth & A well-known brand & Texture (gel, cream) \\
& Cleaning & Packaging & User-friendly menu & A nice smell \\
Against dental plaque & A well-known brand & Short start-up time & Price-quality relationship \\
Against teeth sensitivity & Presence of extra ingredients & User-friendly remote control & Hypoallergenic (= little or no \\
A rell known brand & (caffeine, tea extracts) & Recording possibilities & Working against a specific \\
Quality & & (recorder, hard disk) & skin problem (e.g., oily \\
& & Technical possibilities & (HDMI,USB port,...) & Price attribute \\
& & & Prin, redness)
\end{tabular}


Enhances my confidence

Fresh taste in my mouth

Less dental caries

Easy to use

Makes brushing enjoyable

Clean teeth

Less dental plaque

Helps me feel good

Healthy teeth

Less dental pain

Brand ensures quality

Sacrifices

Budget-friendly (R)

Sacrifices

Budget-friendly (R)
Nice feeling drinking this SD

Gives me energy

I won't get fat

Bloated feeling (R)

Refreshing

Brand ensures quality
Looks good in my interior

Quick start up

Allows me to record movies and programs

Energy-saving

Brand ensures quality

Meets my needs
Makes my skin feel pleasant Helps keeping skin healthy Applying this DC feels nice Feel clean Refreshing Brand ensures quality

This choice saves me money $(R)$ This choice saves me money $(R)$ This choice saves me money $(R)$ This choice saves me money $(R)$

\section{Appendix B}

\section{Dodds et al. (1991)}

\begin{tabular}{|c|c|c|c|c|c|}
\hline & & TP & SD & DVD & DC \\
\hline & & \multicolumn{4}{|c|}{ Item loadings } \\
\hline \multicolumn{2}{|l|}{ 1. This $X$ is a very good value for the money } & $.80^{* *}$ & $.81^{* *}$ & $.88^{* *}$ & $.82 * *$ \\
\hline \multicolumn{2}{|l|}{ 2. At the price shown this $X$ is very economical. } & $.73 * *$ & $.82 * *$ & $.69 * *$ & $.78^{* *}$ \\
\hline \multicolumn{2}{|l|}{ 3. This is a good buy. } & $.82 * *$ & $.86^{* *}$ & $.89 * *$ & $.88^{* *}$ \\
\hline \multicolumn{2}{|l|}{ 4. The price shown for this $\mathrm{X}$ is unacceptable. $(\mathrm{R})$} & $.42 * *$ & $.53 * *$ & $.44 * *$ & $.65^{* *}$ \\
\hline \multirow[t]{6}{*}{ 5. This $X$ appears to be a bargain. } & & $.37 * *$ & $.68 * *$ & $.43 * *$ & $.51 * *$ \\
\hline & & \multicolumn{4}{|c|}{ Construct-level psychometric properties } \\
\hline & $\lambda_{1}$ & 2.27 & 2.93 & 2.57 & 2.89 \\
\hline & $\lambda_{2}$ & 1.14 & .88 & 1.03 & .90 \\
\hline & $\alpha^{\mathrm{a}}$ & & .81 & & .81 \\
\hline & $\mathrm{AVE}^{\mathrm{a}}$ & & .56 & & .55 \\
\hline
\end{tabular}

Note: $(\mathrm{R})=$ reverse scored; $\mathrm{X}$ stands for toothpaste, soft drink, DVD player or day cream.

$\mathrm{TP}=$ toothpaste; $\mathrm{SD}=$ soft drink; DVD $=\mathrm{DVD}$ player; $\mathrm{DC}=$ day cream.

$\lambda_{1}$ and $\lambda_{2}=$ eigenvalues that are used to evaluate unidimensionality of the scale; $\alpha=$ Cronbach's alpha, which is used to evaluate the reliability of the scale; $\mathrm{AVE}=$ Average Variance Extracted, which is used to evaluate within method convergent validity

${ }^{a}$ Since the scale was not unidimensional for think offerings,we did not evaluate Cronbach's alpha and AVE for the toothpaste and DVD settings ${ }^{*} p<.10 * * p<.05$ 
Gale (1994)

(The items [attributes] are presented in Appendix A)

\section{Importance}

Please indicate how important each of the following characteristics of toothpaste/day cream/soft drink/DVD players is to you.

Performance (following Babakus et al. (2004))

Please indicate how you evaluate your toothpaste/day cream/ soft drink/DVD player relative to the competition.

Market Perceived Quality:

$M P Q=\sum_{i=1}^{n} w_{i} R P Q_{i}$
With

$w_{i} \quad$ normalized weight of quality attribute $\mathrm{i}$

$R P Q_{i} \quad$ relative performance on quality attribute $\mathrm{i}$

Market Perceived Price:

$M P P=\sum_{j=1}^{m} w_{j} R P P_{j}$

With

$w_{j} \quad$ normalized weight of price attribute $\mathrm{j}$

$R P P_{j} \quad$ relative performance on price attribute $\mathrm{j}$

\begin{tabular}{llllll}
\hline Item & \multicolumn{2}{c}{ Item loadings } & & & \\
\hline & TP & SD & DVD & \\
MPQ & $.98^{* *}$ & $1.00^{* *}$ & $1.00^{* *}$ & DC \\
MPP & $-.24^{* *}$ & $-.23^{* *}$ & $-.31^{* *}$ & $1.00^{* *}$ \\
& & & $-.31^{* *}$ \\
\hline
\end{tabular}

${ }^{*} p<.10 * * p<.05$

Woodruff and Gardial (1996)

(The items [consequences] are presented in Appendix A)

\begin{tabular}{|c|c|c|c|c|}
\hline Benefits & $\mathbf{T P}$ & SD & DVD & DC \\
\hline \multicolumn{5}{|c|}{ Item loadings } \\
\hline BEN1 & $.56^{* *}$ & $.83^{* *}$ & $.77 * *$ & $.77 * *$ \\
\hline BEN2 & $.46^{* *}$ & $.65^{* *}$ & $.76^{* *}$ & $.77 * *$ \\
\hline BEN3 & $.42 * *$ & $.36^{* *}$ & $.77 * *$ & $.65 * *$ \\
\hline BEN4 & $.29 * *$ & $.64 * *$ & $.54 * *$ & $.88^{* *}$ \\
\hline BEN5 & $.50 * *$ & $.47 * *$ & $.58 * *$ & $.92 * *$ \\
\hline BEN6 & $.58^{* *}$ & $.31 * *$ & $.20 * *$ & $.66^{* *}$ \\
\hline BEN7 & $.62 * *$ & $.23 * *$ & $.51 * *$ & $.72 * *$ \\
\hline BEN8 & $.69 * *$ & $.73 * *$ & $.70 * *$ & $.72 * *$ \\
\hline BEN9 & $.78^{* *}$ & $.61^{* *}$ & $.79 * *$ & $.77 * *$ \\
\hline BEN10 & $.69^{* *}$ & & & \\
\hline BEN11 & $.62 * *$ & & & \\
\hline BEN12 & $.70 * *$ & & & \\
\hline BEN13 & $.61^{* *}$ & & & \\
\hline \multirow[t]{3}{*}{ BEN14 } & $.85^{* *}$ & & & \\
\hline & Second- & & & \\
\hline & $1.00 * *$ & $1.00^{* *}$ & $1.00 * *$ & $1.00 * *$ \\
\hline
\end{tabular}




\begin{tabular}{|c|c|c|c|c|c|}
\hline \multirow[t]{2}{*}{ Sacrifices } & & TP & SD & DVD & DC \\
\hline & & \multicolumn{4}{|c|}{ Item loadings } \\
\hline $\mathrm{SAC} 1$ & & $.96^{* *}$ & $.97 * *$ & $.97 * *$ & $.96 * *$ \\
\hline \multirow{8}{*}{$\mathrm{SAC} 2$} & & $.92 * *$ & $.92 * *$ & $.70 * *$ & $.96 * *$ \\
\hline & & \multicolumn{4}{|c|}{ Construct-level psychometric properties } \\
\hline & $\lambda_{1}$ & 1.76 & 1.79 & 1.50 & 1.85 \\
\hline & $\lambda_{2}$ & .24 & .21 & .50 & .15 \\
\hline & $\alpha$ & .92 & .88 & .67 & .92 \\
\hline & AVE & .88 & .89 & .71 & .92 \\
\hline & & \multicolumn{4}{|c|}{ Second-order loadings } \\
\hline & & $-.32 * *$ & -.14 & $-.29 * *$ & $-.40 * *$ \\
\hline
\end{tabular}

Note: $\mathrm{TP}=$ toothpaste; $\mathrm{SD}=$ soft drink $\mathrm{DVD}=\mathrm{DVD}$ player; $\mathrm{DC}=$ day cream.

$\lambda_{1}$ and $\lambda_{2}=$ eigenvalues that are used to evaluate unidimensionality of the scale; $\alpha=$ Cronbach's alpha, which is used to evaluate the reliability of the scale; $\mathrm{AVE}=$ Average Variance Extracted, which is used to evaluate within method convergent validity

${ }^{*} p<.10 * * p<.05$

\section{Holbrook (1999)}

Social value (adapted from Sweeney and Soutar (2001))

Helps me to feel acceptable.

Improves the way I am perceived.

Makes a good impression on others.

Gives me social approval.

\section{TP}

Item loadings

$\begin{array}{llll}.94^{* *} & .95^{* *} & .98^{* *} & .85^{* *} \\ .95^{* *} & .97^{* *} & .99^{* *} & .94^{* *} \\ .91^{* *} & .92^{* *} & .81^{* *} & .95^{* *} \\ .91^{* *} & .95^{* *} & .95^{* *} & .90^{* *}\end{array}$

Construct-level psychometric properties

$\lambda_{1}$
$\lambda_{2}$
$\alpha$
AVE

AVE

Play (adapted from Petrick (2002))

Makes me feel good.

Gives me pleasure.

Gives me a sense of joy.

Makes me feel delighted.

Gives me happiness.

Excellence (adapted from Oliver (1997))

The quality is excellent.

One of the best regarding quality.

High quality product.

Superior compared to competing products.

$\begin{array}{rrrr}3.45 & 3.60 & 3.55 & 3.34 \\ .23 & .25 & .30 & .32 \\ .95 & .96 & .96 & .93 \\ .86 & .90 & .87 & .83\end{array}$

Second-order loadings

.09

.03

$-.14$
TP

SD

Item loadings

$\begin{array}{ll}.82 * * & .82 * * \\ .91 * * & .90 * * \\ .95 * * & .95 * * \\ .91 * * & .96 * * \\ .91 * * & .95 * *\end{array}$

Construct-level psychometric properties

$\lambda_{1}$
$\lambda_{2}$
$\alpha$
AVE

AVE

$$
4.20
$$

.42

.95

.84
4.09

.56

.94

.81

Seco
47

TP

Item loadings
$.87 * *$

$.93 * *$

$.95 * *$

$.84 * *$
SD

$.92 * *$

$.94 * *$

$.94 * *$

$.85^{* *}$
DVD

$$
.58^{* *}
$$$$
.81 * *
$$$$
.90 * *
$$$$
.85^{* *}
$$$$
.82 * *
$$

3.42

.76

.88

.64

.35

DVD

DC

$.88 * *$
$.92 * *$
$.93 * *$
$.82 * *$




\begin{tabular}{llrrr}
\multicolumn{5}{l}{ Construct-level psychometric properties } \\
$\lambda_{1}$ & 3.23 & 3.35 & 3.00 & 3.17 \\
$\lambda_{2}$ & .41 & .36 & .51 & .48 \\
$\alpha$ & .92 & .93 & .89 & .91 \\
AVE & .81 & .84 & .75 & .79 \\
& \multicolumn{2}{l}{ Second-order loadings } & & \\
& .99 & .98 & .91 & .96 \\
& & & & \\
& TP & SD & DVD & DC \\
& Item loadings & & & $.95^{* *}$ \\
& $.59^{* *}$ & $.96^{* *}$ & & $.96^{* *}$ \\
& & & &
\end{tabular}

.$\lambda_{1}$
.$\lambda$
$\mathrm{A}_{2}$
AVE

I think I look good by using

this TP/DC/SD.

I think my teeth/skin is beautiful

by using this TP/DC.

I think I have a fresh breath by using this toothpaste.

I think I have a nice figure by drinking this soft drink.

I think this DVD player is beautiful.

This DVD player looks good in my interior.

This DVD player has a beautiful design.

This DVD player has a beautiful color.
Construct-level psychometric properties

$.93 * *$

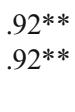

$.95^{* *}$

$.93^{* *}$

Construct-level psychometric properties

$\begin{array}{rrr}1.79 & 3.46 & 1.82 \\ .21 & .22 & .18 \\ .88 & .95 & .90 \\ .89 & .86 & .91 \\ \text { dings } & & .79 \\ .21 & .55 & \end{array}$

Second-order loadings

.65

SD

DVD

DC

Item loadings

$\begin{array}{llll}.05 & .78 & -.15 & .05 \\ .35 * & .07\end{array}$

The price is high $(\mathrm{R})$

The effort I expend to receive

$.35^{*}$

$-.55$

.07

.24

$.98^{* *}$

$.86^{* *}$

$.48^{* *}$

$.99 * *$

This TP/DC/DVD is easy to use

Starting up the DVD player

requires a lot of time (i.e., the time

between turning on the DVD

player and the moment the

DVD starts). (R)
Second-order loadings

.42

00

.68

.47

Note: $(\mathrm{R})=$ reverse scored; $\mathrm{X}$ stands for toothpaste, soft drink, DVD player or day cream.

$\mathrm{TP}=$ toothpaste; $\mathrm{SD}=$ soft drink; DVD $=$ DVD player; $\mathrm{DC}=$ day cream.

$\lambda_{1}$ and $\lambda_{2}=$ eigenvalues that are used to evaluate unidimensionality of the scale; $\alpha=$ Cronbach's alpha, which is used to evaluate the reliability of the scale; AVE $=$ Average Variance Extracted, which is used to evaluate within method convergent validity

${ }^{*} p<.10 * * p<.05$

Satisfaction (adapted from Anderson et al. (1994))

Please indicate the extent to which you are satisfied or dissatisfied with your toothpaste/day cream/soft drink/DVD player. (11-point scale following Wirtz and Lee (2003))
Loyalty (adapted from Zeithaml et al. (1996))

Please indicate how likely it is that you would...

1. Say positive things about your toothpaste/day cream/soft drink/DVD player to other people. 
2. Recommend your toothpaste/day cream/soft drink/DVD player to someone who seeks your advice.

3. Encourage friends and relatives to buy this toothpaste/day cream/soft drink/DVD player.

4. Consider this toothpaste/day cream/soft drink/DVD player your first choice to buy toothpaste/day cream/soft drink/DVD player.

5. Buy this toothpaste/day cream/soft drink/DVD player again when you need toothpaste/day cream/soft drink/DVD player.

6. Doubt about buying this toothpaste/day cream/soft drink/ DVD player again.

\section{References}

Agarwal, S., \& Teas, R. K. (2001). Perceived value: mediating role of perceived risk. Journal of Marketing Theory and Practice, 9(4), 114.

Anderson, E. W., Fornell, C., \& Lehmann, D. R. (1994). Customer satisfaction, market share, and profitability: findings from Sweden. Journal of Marketing, 58(3), 53-66.

Anderson, E. W., Fornell, C., \& Mazvancheryl, S. K. (2004). Customer satisfaction and shareholder value. Journal of Marketing, 68(4), $172-185$.

Anderson, E. W., Fornell, C., \& Rust, R. T. (1997). Customer satisfaction, productivity, and profitability: differences between goods and services. Marketing Science, 16(2), 129-145.

Babakus, E., Bienstock, C. C., \& Van Scotter, J. R. (2004). Linking perceived quality and customer satisfaction to store traffic and revenue growth. Decision Sciences, 35(4), 713-737.

Bagozzi, R. P. (1992). The self regulation of attitudes, intentions, and behavior. Social Psychology Quarterly, 55, 178-204.

Baker, J., Parasuraman, A., Grewal, D., \& Voss, G. B. (2002). The influence of multiple store environment cues on perceived merchandise value and patronage intentions. Journal of Marketing, 66(2), $120-141$.

Bernhardt, K. L., Donthu, N., \& Kennett, P. A. (2000). A longitudinal analysis of satisfaction and profitability. Journal of Business Research, 47(2), 161-171.

Bevan, J., \& Murphy, R. (2001). The nature of value created by UK online grocery retailers. International Journal of Consumer Studies, 25(4), 279-289.

Blocker, C. P., Flint, D. J., Myers, M. B., \& Slater, S. F. (2011). Proactive customer orientation and its role for creating customer value in global markets. Journal of the Academy of Marketing Science, 39(2), 216-233.

Bolton, R. N., \& Drew, J. H. (1991). A multistage model of customers' assessments of service quality and value. Journal of Consumer Research, 17(4), 375-384.

Bourdeau, L., Chebat, J. C., \& Couturier, C. (2002). Internet consumer value of university students: e-mail-vs.-Web users. Journal of Retailing and Consumer Services, 9, 61-69.

Caruana, A., \& Fenech, N. (2005). The effect of perceived value and overall satisfaction on loyalty: a study among dental patients. Journal of Medical Marketing, 5(3), 245-255.

Chan, K. W., Yim, C. K., \& Lam, S. S. K. (2010). Is customer participation in value creation a double-edged sword? Evidence from professional financial services across cultures. Journal of Marketing, 74(3), 48-64

Chen, Z., \& Dubinsky, A. J. (2003). A conceptual model of perceived customer value in E-commerce: a preliminary investigation. Psychology \& Marketing, 20(4), 323-347.
Chin, W. W. (2010). How to write up and report PLS analyses. In V. Esposito Vinzi, W. Chin, J. Henseler, \& H. Wang (Eds.), Handbook of partial least squares. Concepts, methods and applications (pp. 655-690). Berlin: Springer.

Cronin, J. J., Jr., Brady, M. K., \& Hult, G. T. M. (2000). Assessing the effects of quality, value, and customer satisfaction on consumer behavioral intentions in service environments. Journal of Retailing, 76(2), 193-218.

Deutskens, E., de Ruyter, K., Wetzels, M., \& Oosterveld, P. (2004). Response rate and response quality of Internet-based surveys: an experimental study. Marketing Letters, 15(1), 21-36.

Devlin, S. J., Dong, H. K., \& Brown, M. (2003). Selecting a scale for measuring quality. Marketing Research, 15(3), 13-16.

Diamantopoulos, A., \& Winklhofer, H. M. (2001). Index construction with formative indicators: an alternative to scale development. Journal of Marketing Research, 38(2), 269-277.

Dodds, W. B., Monroe, K. B., \& Grewal, D. (1991). Effects of price, brand, and store information on buyers' product evaluations. Journal of Marketing Research, 28(3), 307-319.

Drolet, A. L., \& Morrison, D. G. (2001). Do we really need multiple-item measures in services research? Journal of Service Research, 3(3), 196-204.

Flint, D. J., Woodruff, R. B., \& Gardial, S. F. (2002). Exploring the phenomenon of customers' desired value change in a business-tobusiness context. Journal of Marketing, 66(4), 102-117.

Fornell, C., \& Larcker, D. F. (1981). Evaluating structural equation models with unobservable variables and measurement error. Journal of Marketing Research, 18(1), 39-50.

Fornell, C., Mithas, S., Morgeson, F., \& Krishnan, M. S. (2006). Customer satisfaction and stock prices: high returns, low risk. Journal of Marketing, 70(1), 3-14.

Fornell, C., Rust, R., \& Dekimpe, M. G. (2010). The effect of customer satisfaction on consumer spending growth. Journal of Marketing Research, 47(1), 28-35.

Gale, B. T. (1994). Managing customer value: Creating quality and service that customers can see. New York: Free Press.

Gallarza, M. G., \& Gil-Saura, I. (2006). Value dimensions, perceived value, satisfaction and loyalty: an investigation of university students' travel behavior. Tourism Management, 27(3), 437-452.

Gerbing, D. W., \& Anderson, J. C. (1988). An updated paradigm fro scale development incorporating unidimensionality and its assessment. Journal of Marketing Research, 25(2), 186-192.

Gotlieb, J. B., Grewal, D., \& Brown, S. W. (1994). Consumer satisfaction and perceived quality: complementary or divergence constructs. Journal of Applied Psychology, 79(6), 875-885.

Graeff, T. R. (1997). Comprehending product attributes and benefits: the role of product knowledge and means-end chain inferences. Psychology \& Marketing, 14(2), 163-183.

Grönroos, C. (2011). Service as business logic: implications for value creation and marketing. Journal of Service Management, 22(1), 5 22.

Grönroos, C., \& Ravald, A. (2011). Service as business logic: implications for value creation and marketing. Journal of Services Management, 22(1), 5-22.

Grönroos, C., \& Voima, P. (2013). Critical service logic: making sense of value creation and co-creation. Journal of the Academy of Marketing Science, 41(2), 133-150.

Gruca, T. S., \& Rego, L. L. (2005). Customer satisfaction, cashflow, and shareholder value. Journal of Marketing, 69(3), 115-130.

Gutman, J. (1982). A means-end chain model based on consumer categorization processes. Journal of Marketing, 46(2), 60-72.

Hair, J. F., Ringle, C. M., \& Sarstedt, M. (2011). PLS-SEM: indeed a silver bullet. Journal of Marketing Theory and Practice, 19(2), 139151.

Holbrook, M. B. (1999). Consumer value: A framework for analysis and research. London: Routledge. 
Holbrook, M. B. (2006). Consumption experience, customer value, and subjective personal introspection: an illustrative photographic essay. Journal of Business Research, 59(6), 714-725.

Ittner, C. D., \& Larcker, D. F. (1998). Are nonfinancial measures leading indicators of financial performance? An analysis of customer satisfaction. Journal of Accounting Research, 36, 1-35.

Jarvis, C. B., MacKenzie, S. B., \& Podsakoff, P. M. (2003). A critical review of construct indicators and measurement model misspecification in marketing and consumer research. Journal of Consumer Research, 30(2), 199-218.

Karlis, D., Saporta, G., \& Spinakis, A. (2003). A simple rule for the selection of principal components. Communications in Statistics: Theory and Methods, 32(3), 643-666.

Lai, F., Griffin, M., \& Babin, B. J. (2009). How quality, value, image, and satisfaction create loyalty at a Chinese telecom. Journal of Business Research, 62(10), 980-986.

Laitamäki, J., \& Kordupleski, R. (1997). Building and deploying profitable growth strategies based on the waterfall of customer value added. European Management Journal, 15(2), 158-166.

Lam, S. Y., Shankar, V., Erramilli, M. K., \& Murthy, B. (2004). Customer value, satisfaction, loyalty, and switching costs: an illustration from a business-to-business service context. Journal of the Academy of Marketing Science, 32(3), 293-311.

Lin, C. H., Sher, P. J., \& Shih, H. Y. (2005). Past progress and future directions in conceptualizing customer perceived value. International Journal of Service Industry Management, 16(4), 318-336.

Lusch, R. F., \& Vargo, S. L. (2006). The service-dominant logic of marketing: Dialog, debate, and directions. New York: M.E. Sharpe Inc.

MacDonald, E. K., Wilson, H., Martinez, V., \& Toossi, A. (2011). Assessing value-in-use: a conceptual framework and exploratory study. Industrial Marketing Management, 40(5), 671-682.

MacKenzie, S. B., Podsakoff, P. M., \& Jarvis, C. B. (2005). The problem of measurement model misspecification in behavioral and organizational research and some recommended solutions. Journal of Applied Psychology, 90(4), 710-730.

MacKenzie, S. B., Podsakoff, P. M., \& Podsakoff, N. B. (2011). Construct measurement and validation procedures in MIS and behavioral research: Integrating new and existing techniques. MIS Quarterly, 35(2), 293-334.

Mathwick, C., Malhotra, N., \& Rigdon, A. (2001). Experiential value: conceptualization, measurement and application in the catalog and Internet shopping environment. Journal of Retailing, 77(1), 39-56.

Morgan, N. A., \& Rego, L. L. (2006). The value of different customer satisfaction and loyalty metrics in predicting business performance. Marketing Science, 25(5), 426-439.

Mittal, V., Anderson, E. W., Sayrak, A., \& Tadikamalla, P. (2005). Dual emphasis and the long-term financial impact of customer satisfaction. Marketing Science, 24(4), 544-558.

Oliver, R. L. (1997). Satisfaction: A behavioral perspective on the consumer. New York: McGraw-Hill.

Overby, J. W., Gardial, S. F., \& Woodruff, R. B. (2004). French versus American consumers' attachment of value to a product in a common consumption context: a cross-national comparison. Journal of the Academy of Marketing Science, 32(4), 437-460.

Petrick, J. F. (2002). Development of a multi-dimensional scale for measuring the perceived value of a service. Journal of Leisure Research, 34(2), 119-134.

Preacher, K., \& Hayes, A. (2008). Asymptotic and resampling strategies for assessing and comparing indirect effects in multiple mediator models. Behavior Research Methods, 40(3), 879-891.

Ratchford, B. T. (1987). New insights about the FCB grid. Journal of Advertising Research, 27(4), 24-38.

Reinartz, W., Krafft, M., \& Hoyer, W. D. (2004). The customer relationship management process: its measurement and impact on performance. Journal of Marketing Research, $41(3), 293-305$.

Ringle, C. M., Sarstedt, M., \& Straub, D. W. (2012). A critical look at the use of PLS-SEM in MIS Quarterly. MIS Quarterly, 36(1), 3-14.

Rust, R. T., Lemon, K. L., \& Zeithaml, V. A. (2004). Return on marketing: using customer equity to focus marketing strategy. Journal of Marketing, 68(1), 109-127.

Ruiz, D. M., Gremler, D. D., Washburn, J. H., \& Carrión, G. C. (2008). Service value revisited: specifying a higher-order, formative measure. Journal of Business Research, 61 (12), 1278-1291.

Sahmer, K., Hanafi, M., \& Qannari, E. M. (2006). Assessing unidimensionality within PLS path modeling framework. In M. Spiliopoulou, R. Kruse, A. Nürnberger, C. Borgelt, \& W. Gaul (Eds.), From data and information analysis to knowledge engineering (pp. 222-229). Heidelberg: Springer Verlag.

Sánchez-Fernández, R., \& Iniesta-Bonillo, M. A. (2007). The concept of perceived value: a systematic review of the research. Marketing Theory, 7(4), 427-451.

Sánchez-Fernández, R., Iniesta-Bonillo, M. A., \& Holbrook, M. B. (2009). The conceptualisation and measurement of consumer value in services. International Journal of Market Research, 51 (1), 93-113.

Seiders, K., Voss, G. B., Grewal, D., \& Godfrey, A. L. (2005). Do satisfied customers buy more? Examining moderating influences in a retailing context. Journal of Marketing, 69(4), 26-43.

Setijono, D., \& Dahlgaard, J. J. (2007). Customer value as a key performance indicator (KPI) and a key improvement indicator (KII). Measuring Business Excellence, 11 (2), 44-61.

Slater, S. F. (1997). Developing a customer value-based theory of the firm. Journal of the Academy of Marketing Science, 25(2), 162-167.

Smith, N. C. (1999). Ethics and the typology of consumer value. In M. B. Holbrook (Ed.), Consumer value: A framework for analysis and research (pp. 147-158). London: Routledge.

Stewart, T. J. (1992). A critical survey on the status of multiple criteria decision making theory and practice. International Journal of Management Science, 20(5/6), 569-586.

Strauss, A. L., \& Corbin, J. M. (1998). Basics of qualitative research: Techniques and procedures for developing grounded theory. London: Sage Publications.

Sweeney, J. C., \& Soutar, G. N. (2001). Consumer perceived value: the development of a multiple item scale. Journal of Retailing, 77(2), 203-220.

Teas, R. K., \& Agarwal, S. (2000). The effects of extrinsic product cues on consumers' perceptions of quality, sacrifice, and value. Journal of the Academy of Marketing Science, 28(2), 278-290.

Trusov, M., Bucklin, R. E., \& Pauwels, K. (2009). Effects of word-ofmouth versus traditional marketing: findings from an Internet social networking site. Journal of Marketing, 73(5), 90-102.

Ulaga, W., \& Eggert, A. (2006). Value-based differentiation in business relationships: gaining and sustaining key supplier status. Journal of Marketing, 70(1), 119-136.

Vargo, S. L., \& Lusch, R. F. (2004). Evolving to a new dominant logic for marketing. Journal of Marketing, 68(1), 1-17.

Vargo, S. L., Maglio, P. P., \& Akaka, M. A. (2008). On value and value co-creation: a service systems and service logic perspective. European Management Journal, 26(3), 145-152.

Vaughn, R. (1980). How advertising works: a planning model. Journal of Advertising Research, 20(5), 27-33.

Villanueva, J., Yoo, S., \& Hanssens, D. M. (2008). The impact of marketinginduced versus word-of-mouth customer acquisition on customer equity growth. Journal of Marketing Research, 45(1), 48-59.

Wirtz, J., \& Lee, M. C. (2003). An examination of the quality and context-specific applicability of commonly used customer satisfaction measures. Journal of Service Research, 5(4), 345-355.

Woodall, T. (2003). Conceptualising 'value for the customer': an attributional, structural and dispositional analysis. Academy of Marketing Science Review, 12, 1-42. 
Woodruff, R. B. (1997). Customer value: the next source for competitive advantage. Journal of the Academy of Marketing Science, 25(2), $139-153$.

Woodruff, R. B., \& Gardial, S. F. (1996). Know your customer: New approaches to understanding customer value and satisfaction. Cambridge: Blackwell Publications.

Woodruff, R. B., \& Flint, D. J. (2006). Marketing's service-dominant logic and customer value. In R. F. Lusch \& S. L. Vargo (Eds.), The service-dominant logic of marketing: Dialog, debate, and directions (pp. 183-195). New York: M.E. Sharpe Inc.

Zar, J. H. (1996). Biostatistical analysis. New Jersey: Prentice-Hall.

Zeithaml, V. A. (1988). Consumer perceptions of price, quality, and value: a means-end model and synthesis of evidence. Journal of Marketing, 52(2), 2-22.

Zeithaml, V. A., Berry, L. L., \& Parasuraman, A. (1996). The behavioral consequences of service quality. Journal of Marketing, 60(2), 31-46. 